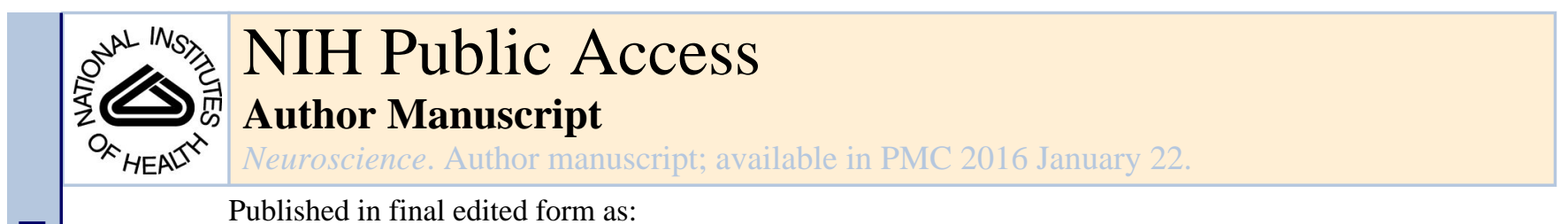

Published in final edited form as:

Neuroscience. 2015 January 22; 0: 775-797. doi:10.1016/j.neuroscience.2014.10.044.

\title{
Early-life Exposure to the SSRI Paroxetine Exacerbates Depression-like Behavior in Anxiety/Depression-prone rats
}

\author{
Matthew E. Glover ${ }^{1}$, Phyllis C. Pugh ${ }^{1}$, Nateka L. Jackson ${ }^{1}$, Joshua L. Cohen ${ }^{1}$, Andrew D. \\ Fant $^{2}$, Huda Akil ${ }^{3}$, and Sarah M. Clinton ${ }^{1, \S}$ \\ ${ }^{1}$ Department of Psychiatry and Behavioral Neurobiology, University of Alabama-Birmingham, \\ USA \\ ${ }^{2}$ Division of Chemical Biology and Medicinal Chemistry, Eshelman School of Pharmacy, \\ University of North Carolina at Chapel Hill, USA \\ ${ }^{3}$ Molecular and Behavioral Neuroscience Institute, University of Michigan, USA
}

\section{Abstract}

Selective serotonin reuptake inhibitor (SSRI) antidepressants are the mainstay treatment for the 10-20\% of pregnant and postpartum women who suffer major depression, but the effects of SSRIs on their children's developing brain and later emotional health are poorly understood. SSRI use during pregnancy can elicit antidepressant withdrawal in newborns and increase toddlers' anxiety and social avoidance. In rodents, perinatal SSRI exposure increases adult depression- and anxietylike behavior, although certain individuals are more vulnerable to these effects than others. Our study establishes a rodent model of individual differences in susceptibility to perinatal SSRI exposure, utilizing selectively-bred Low Responder (bLR) and High Responder (bHR) rats that were previously bred for high versus low behavioral response to novelty. Pregnant bHR/bLR females were chronically treated with the SSRI paroxetine (10 mg/kg/day p.o.) to examine its effects on offspring's emotional behavior and gene expression in the developing brain. Paroxetine treatment had minimal effect on bHR/bLR dams' pregnancy outcomes or maternal behavior. We found that bLR offspring, naturally prone to an inhibited/anxious temperament, were susceptible to behavioral abnormalities associated with perinatal SSRI exposure (which exacerbated their Forced Swim test immobility), while high risk-taking bHR offspring were resistant. Microarray studies revealed robust perinatal SSRI-induced gene expression changes in the developing bLR hippocampus and amygdala (postnatal days 7-21), including transcripts involved in neurogenesis,

(C) 2014 IBRO. Elsevier Ltd. All rights reserved.

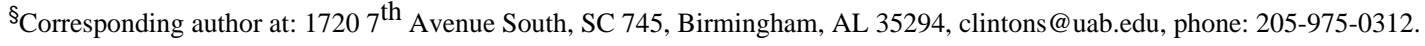

\section{Contributors Statement}

The primary author, Matthew Glover, collected samples for the microarray and HPLC analyses, analyzed the microarray data, monitored maternal behavior, and co-wrote the manuscript with Dr. Sarah Clinton. Nateka Jackson set up the breeding of bHR and bLR animals, and assisted in maternal behavior monitoring, and sample collection for HPLC. Joshua Cohen, Andrew Fant, Dr. Phyllis Pugh contributed to the microarray analysis and together with Dr. Huda Akil, provided critical discussion of data analysis and interpretation as well as editorial comments on the manuscript. Dr. Sarah Clinton designed and conducted the pharmacological and behavioral studies. All authors contributed to and have approved the final version of the manuscript.

Publisher's Disclaimer: This is a PDF file of an unedited manuscript that has been accepted for publication. As a service to our customers we are providing this early version of the manuscript. The manuscript will undergo copyediting, typesetting, and review of the resulting proof before it is published in its final citable form. Please note that during the production process errors may be discovered which could affect the content, and all legal disclaimers that apply to the journal pertain. 
synaptic vesicle components, and energy metabolism. These results highlight the bLR/bHR model as a useful tool to explore the neurobiology of individual differences in susceptibility to perinatal SSRI exposure.

\section{Keywords}

depression; anxiety; neurodevelopment; hippocampus; amygdala; antidepressant

\section{Introduction}

Depression is one of the most prevalent and debilitating mental illnesses in the United States (Kessler et al., 2003). While it typically manifests in early adulthood (Kessler et al., 2003), neural circuits thought to underlie depression are sensitive to early-life environmental factors, including exposure to stress, drugs, maternal style and poor maternal mood (Ladd C.O., 2000, Heim C., 2004, Marcus, 2009, Oberlander et al., 2009). Women are 70\% more likely to develop depression than men, with peak prevalence occurring during the childbearing years (Dayan et al., 2002, Bennett et al., 2004, Kessler RC, 2005, Borri et al., 2008, Marcus, 2009, Yonkers et al., 2009). Selective serotonin reuptake inhibitor (SSRI) antidepressants are the mainstay treatment for the 10-20\% of pregnant and postpartum women who suffer major depression (Dayan et al., 2002, Bennett et al., 2004, Borri et al., 2008, Marcus, 2009, Yonkers et al., 2009), exposing tens of thousands of children annually to serotonergic agents during crucial developmental periods. These medications are generally considered safe, with limited incidence of SSRI-related birth abnormalities and pregnancy complications (Grigoriadis et al., 2013, Ross et al., 2013, Vasilakis-Scaramozza et al., 2013). In 2005, the FDA issued a warning against using the SSRI paroxetine during pregnancy due to reports of fetal cardiovascular malformation (Kallen and Otterblad Olausson, 2006, Bar-Oz et al., 2007). Similar concerns were raised for other SSRIs, including fluoxetine (Diav-Citrin et al., 2008, Jimenez-Solem et al., 2012), citalopram (Pedersen et al., 2009, Jimenez-Solem et al., 2012) and sertraline (Louik et al., 2007, Pedersen et al., 2009, Kornum et al., 2010, Jimenez-Solem et al., 2012), although subsequent studies concluded that the effects were small and that SSRIs generally pose minimal teratogenic risks (Malm et al., 2005, Wogelius et al., 2006, Alwan et al., 2007, Berard et al., 2007, Cole et al., 2007, Louik et al., 2007, Diav-Citrin et al., 2008, Einarson et al., 2008, Oberlander et al., 2008c, Pedersen et al., 2009, Bakker et al., 2010, Kornum et al., 2010).

There are several reports of a neonatal withdrawal syndrome (altered sleep, heart rate variability, jitteriness) in newborns exposed to different types of SSRIs in utero (Zeskind and Stephens, 2004, Alwan and Friedman, 2009, Gentile and Galbally, 2011, Hayes et al., 2012). Infants and young children exposed to SSRIs during early-life can also exhibit subtle psychomotor deficits (Casper et al., 2003), aberrant pain sensation (Oberlander et al., 2005), altered hypothalamic pituitary adrenal stress responses (Oberlander et al., 2008b), increased social avoidance and anxiety at age 3-4 (Oberlander et al., 2010, Klinger et al., 2011), and increased risk for autism (Croen, 2011, Harrington et al., 2013, Rai, 2013) (although there are conflicting reports on the risk for autism; see (Clements et al., 2014)). Human studies 
have not extended beyond childhood, so the long-term consequences of early-life SSRI exposure on human brain maturation and behavior remain unknown.

SSRIs elevate synaptic serotonin (5-hydroxytryptamine, 5HT) levels by blocking its reuptake transporter (SERT). Because 5HT influences myriad neurodevelopmental processes including cell differentiation and migration, synaptogenesis, dendritic maturation and pruning (Gaspar et al., 2003, Homberg et al., 2010, Olivier et al., 2011), neonatal SSRI exposure can interfere with brain development by hindering both 5HT system maturation and 5HT-modulated developmental processes. Rodent studies show that pharmacological or genetic manipulation of the developing 5-HT system produces lifelong behavioral alterations (Maciag et al., 2006a, Ansorge et al., 2008, Noorlander et al., 2008, Popa et al., 2008). For example, early-life exposure to tricyclic antidepressants or different types of SSRIs produces adult behavioral abnormalities that resemble human depression, including increased Forced Swim Test (FST) immobility, enhanced anxiety-like behavior, anhedonia, perturbed sleep, and diminished sexual performance (Mirmiran et al., 1981, Hilakivi and Hilakivi, 1987, Vogel et al., 1990, Velazquez-Moctezuma and Diaz Ruiz, 1992, Hansen et al., 1997, Ansorge et al., 2004, Maciag et al., 2006a, Ansorge et al., 2008, Hartley et al., 2008, Popa et al., 2008, Simpson et al., 2011). Importantly, these behavioral effects are reasonably consistent across several studies, regardless of the specific SSRI or tricyclic antidepressant used. Neonatal antidepressant exposure-induced behavioral abnormalities are accompanied by myriad 5-HT system changes, including reduced neuronal firing in 5-HT neurons of the dorsal raphe (Kinney et al., 1997), diminished expression of tryptophan hydroxylase (TPH2) and SERT in the raphe (Maciag et al., 2006a), reduced 5-HT fiber density in the hippocampus (Weaver et al., 2010), and altered monoamine levels in multiple brain regions (Hilakivi et al., 1987a, Feenstra et al., 1996, Vijayakumar and Meti, 1999, Yannielli et al., 1999).

Studies in humans (Oberlander et al., 2008a, Oberlander et al., 2010) and animals (Bairy et al., 2007, Lisboa et al., 2007, Bourke et al., 2013b) suggest that certain individuals are more vulnerable to the effects of early-life SSRI exposure than others, but mechanisms driving this differential susceptibility are completely unknown, representing a critical barrier in the field (Oberlander et al., 2009, Oberlander, 2012). Thus, a major goal of the present study was to model the phenomenon of individual differences in susceptibility to early-life SSRI exposure to permit investigation of neurobiological factors conveying vulnerability (or resistance) to the effects of this treatment. To this end, we utilized our selectively-bred lines of Sprague Dawley rats that display marked differences in emotional behavior and 5HT circuitry to determine whether they would also display distinct vulnerabilities to neonatal SSRI exposure. Rats bred for low response to novelty (bLR) display high levels of behavioral inhibition, spontaneous anxiety and depression-like behavior compared to bred High Responder (bHR) rats (Stead et al., 2006a, Clinton et al., 2011b, Garcia-Fuster et al., 2011, Stedenfeld et al., 2011, Cummings et al., 2013). The bHR/bLR rats exhibit 5HT circuit differences that likely contribute to their disparate behavioral phenotypes, with adult bLR rats exhibiting lower Tph2 and Sert mRNA in the dorsal raphe (Kerman et al., 2011) and increased 5HT receptor mRNA levels in multiple limbic brain regions compared to bHRs (Ballaz et al., 2007b, Calvo et al., 2011, Clinton et al., 2011a). 
Based on known bHR/bLR 5-HT circuit differences, we hypothesized that (1) treating adult bLRs with the SSRI paroxetine would improve their depression-like behavior; and (2) earlylife paroxetine exposure would differentially affect bLR versus bHR offspring, with bLRs being more vulnerable to its behavioral consequences than bHRs. In Experiment 1, we chronically treated adult bHR/bLR males with paroxetine to determine whether it would improve bLRs' typically high level of depression- and anxiety-like behavior. In Experiment 2 , bHR/bLR females were chronically treated with paroxetine throughout pregnancy and the postpartum lactation period to determine paroxetine's effect(s) on their adult offspring's behavior. Experiment 3 utilized genome-wide expression profiling in the developing and adult brains of perinatal paroxetine- and vehicle-exposed bLR offspring (focusing on the hippocampus and amygdala - 5-HT innervated brain areas that are particularly impacted by early-life exposure to the SSRI citalopram (Weaver et al., 2010)) to identify novel molecular changes that may trigger the effects of early-life SSRI exposure on brain development and emotional behavior. An additional benefit of this study was that it examined neural and behavioral effects of early-life SSRI exposure in a model animal that is relevant to human depression, which distinguishes it from prior work examining the effects of perinatal antidepressant exposure in "normal/healthy" rats and mice.

\section{Experimental Procedures}

All experiments were approved by the University Committee on the Use and Care of Animals at the University of Michigan where the behavioral studies and tissue harvest were conducted. Work was conducted in accordance with the National Institute of Health (NIH) Guide for the Care and Use of Laboratory Animals, dictated by the National Research Council in 1996.

\subsection{Animals}

The bHR/bLR Sprague-Dawley rats were acquired from the $25^{\text {th }}, 26^{\text {th }}$, and $28^{\text {th }}$ generations of the colony maintained at the University of Michigan in Dr. Akil's laboratory. We previously described our breeding strategy and initial behavioral characterization of the bHR/bLR lines (Stead et al., 2006a). In brief, Sprague-Dawley rats were selected and mated according to locomotor response to a novelty (number of beam breaks made during a 1 hour period in a novel cage). At the first generation, male and female rats with the top (bHR) and bottom (bLR) $20 \%$ of locomotion scores were selected for breeding. Adult males and females from each subsequent generation were screened for locomotor response to novelty, and the most extreme bHR/bLR animals from each family were selected to perpetuate the colony (Stead et al., 2006a). Males that were used for mating or later experiments were kept on a 12:12 light-dark cycle (lights on at 6 a.m.) with food and water available ad libitum. Female rats (as well as male-female mating pairs) were housed in a separate room kept on a 14:10 light-dark cycle to promote regular estrous cycles and fertility (Everett and Sawyer, 1949, Ying et al., 1973). The animal housing rooms and testing facilities were kept at 21$23^{\circ} \mathrm{C}$ at $50-55 \%$ humidity.

Experiment 1 of the present study used a group of adult bHR and bLR males (approximately 8 weeks old), which were subjected to chronic paroxetine (or vehicle) treatment ( $\mathrm{n}=12$ per experimental group), followed by a behavioral test battery described below. Experiment 2 
used adult bHR and bLR females (approximately 8 weeks old), which were subjected to paroxetine (or vehicle) treatment throughout pregnancy and the postpartum lactation period until weaning on postpartum day 21 ( $n=8$ per group). Their male offspring ( $n=24$ per group) were weaned on postnatal day (P) 21, raised under standard laboratory conditions, and evaluated in a behavioral test battery when they reached adulthood (P75). In Experiment 3, another cohort of bLR females was subjected to paroxetine (or vehicle) treatment throughout pregnancy and the postpartum period ( $\mathrm{n}=5$ per group). Brains were harvested from male bLR offspring at four developmental time points (P7, P14, P21 and P75; n=5 pups per group/per time point) to evaluate paroxetine-induced gene expression changes in the developing and adult brain. An additional set of brains were harvested from drug-exposed bLR male offspring at $\mathrm{P} 7$ to confirm drug-levels in brain tissue ( $\mathrm{n}=5$ pups).

\subsection{Paroxetine drug treatment in adult male bHR/bLR rats}

In Experiment 1, male bHR/bLR rats ( $\mathrm{n}=12$ per phenotype per drug treatment group) received the SSRI paroxetine (Sigma-Aldrich, St. Louis, MO; $10 \mathrm{mg} / \mathrm{kg} / \mathrm{day}$ ) over a period of 30 days via drinking water according to previously published protocols(Thompson et al., 2004, Muigg et al., 2007, Karanges et al., 2013). For one week before drug treatment began, we monitored daily water consumption and determined that rats consumed, on average, 10 $\mathrm{ml}$ of water per day per $100 \mathrm{gm}$ of body weight (e.g., a $500 \mathrm{gm}$ male rat consumed approximately $50 \mathrm{ml}$ of water per day). Based on this estimation, paroxetine was dissolved in tap water at a concentration of $0.10 \mathrm{mg} / \mathrm{ml}$ to approach the target dose of $10 \mathrm{mg} / \mathrm{kg} / \mathrm{day}$. The paroxetine solutions were renewed every 2 days, and drug concentrations were calculated according to body weight and water intake of each rat, determined by weighing the drinking bottles at each renewal. The $10 \mathrm{mg} / \mathrm{kg} /$ day dose was selected based on previous literature showing antidepressant and neurochemical effects of paroxetine in adult rats (Carlson et al., 1996, Sillaber et al., 2008). In addition, oral administration of paroxetine at this dose to adolescent and adult rats was previously shown to produce drug plasma concentrations that approximate human therapeutic concentrations $(10-600 \mathrm{ng} / \mathrm{mL})$ (DeVane, 1999, Karanges et al., 2013). Vehicle-treated bHR and bLR animals received normal tap water at each renewal. At the conclusion of the 30-day drug-treatment period (24-h following the last behavioral test), rats were sacrificed by rapid decapitation and blood and brain tissue was collected to assess paroxetine-levels (described below in Section 2.5).

\subsection{Paroxetine drug treatment in pregnant and postpartum bHR/bLR females}

Using the protocol above, bHR/bLR females received paroxetine (10 mg/kg/day p.o.) in drinking water (or drank normal tap water) for 7 days prior to mating, during the mating and pregnancy period, and throughout the three week postpartum lactation period ( $\mathrm{n}=8$ per phenotype per drug treatment group). Male/female pairs were housed together for up to 7 days, with the timing of mating determined by detection of sperm plugs. Once a sperm plug was detected (gestational day 0), the male was removed. During the mating period, the male and female rats were both exposed to paroxetine treatment. As noted above, we generally find that rats consume $10 \mathrm{ml}$ water per day per $100 \mathrm{gm}$ body weight. Thus, female rats (averaging 300 grams each) would typically drink about $30 \mathrm{ml}$ of water per day and male rats (averaging 500 grams each) would typically drink about $50 \mathrm{ml}$ water per day. During the breeding period, when we examined the amount of liquid consumed by a male/female 
pair, we considered their weight differential to estimate what proportion of the liquid was consumed by the male versus the lighter female.

On the day of birth (P0), litters were culled to 6 male and 6 female pups. Offspring that were to be used for Experiment 2 were weaned on P21, with males being housed 3-4 per cage until adulthood when they embarked on a behavioral test battery (described below). Each experimental group ( $\mathrm{n}=24$ males per phenotype per drug exposure group) consisted of 3 littermates from 8 litters. For Experiment 3, we harvested whole brains from bLR male offspring taken at 4 developmental time points (P7, P14, P21, and P75) for gene expression studies ( $n=5$ per phenotype per time point per drug exposure group). For the brains to be collected at the P75 time point, pups were weaned at P21, housed 2-3 per cage, and reared under standard conditions until brains were harvested at P75. At each time point, the $n=5$ per group for the microarray study was comprised of animals from 5 independent litters. An additional group of drug-exposed pups were sacrificed at P7 to determine paroxetine-levels in brain tissue (described below in Section 2.5).

\subsection{Maternal behavioral monitoring}

We observed the behavior of paroxetine- and vehicle-treated bHR/bLR dams from P1-14 using a previously published protocol (Clinton et al., 2010). Each cage was observed twice daily - once during the light phase (at approximately 10:00 a.m.) and once during the dark phase (at approximately 9:00 p.m.). Each observation period (lasting $45 \mathrm{~min}$ to 1 hour) consisted of a series of 105 -sec "snapshot" observations for each cage, which were taken approximately 5 min apart. During a "snapshot" observation, a checklist was used to note which behaviors were being observed. The behaviors noted were: 1) mother licking or grooming a pup; 2) mother resting away from litter; 3) mother passive nursing pups; 4) mother arched-back nursing pups. Passive nursing was defined as the mother lying on her side or back and nursing any number of pups. Arched-back nursing was classified as the mother arched over any number of nursing pups with her legs extended. By the end of the 14 observation days, each cage had accumulated 280 observations ( 10 observations per session $\times 2$ sessions each day $\times 14$ total days).

\subsection{Assessing paroxetine levels in brain and serum}

In Experiment 1, we evaluated paroxetine levels in brain tissue and serum of adult bHR/bLR males that received paroxetine (10 mg/kg/day p.o.) as described in Section 2.2. To assess paroxetine levels in drug-exposed pups, we used tissue harvested during Experiment 3. Whole brains were harvested from P7 drug-exposed bLR pups $(n=5)$ with each animal coming from an independent litter. The P7 time point was chosen to assess the amount of paroxetine that was transferred to offspring through lactation. In each case, animals were sacrificed by rapid decapitation, brains were rapidly removed and flash frozen, and trunk blood was collected from adult rats (there was too little blood from sacrificed pups for serum collection). Brain samples were homogenized in water and stored at $-80^{\circ} \mathrm{C}$. Blood samples were incubated at room temperature for 30-min to allow coagulation and were then spun at $1000 \times \mathrm{g}$ at $4^{\circ} \mathrm{C}$ for $10 \mathrm{~min}$. Serum was then collected in $1.5 \mathrm{ml}$ tubes and stored at $-80^{\circ} \mathrm{C}$. Samples were shipped to NMS Labs (Willowgrove, PA) to measure paroxetine levels via 
High Performance Liquid Chromatography/Tandem Mass Spectroscopy (HPLC/TMS). Data are presented as $\mathrm{ng} / \mathrm{ml}$ for serum samples and $\mu \mathrm{g} / \mathrm{g}$ tissue for brain tissue samples.

\subsection{Behavioral test battery}

In Experiment 1, adult male bHR/bLR rats were chronically treated with paroxetine (10 $\mathrm{mg} / \mathrm{kg} /$ day p.o.) or vehicle (normal tap water) and then evaluated in multiple behavior tests the FST, the Open Field Test, and the Elevated Plus Maze (EPM). In Experiment 2, adult male offspring that were perinatally exposed to paroxetine or vehicle (in utero and P1-21 via maternal drug treatment) were evaluated in the FST and EPM and were also tested for locomotor response to novelty. For both experiments, rats were given 2-3 days of rest between each test to minimize the carry-over effect on behavior from test to test. Prior experiments with bLR/bHR animals used a similar strategy, assessing bLR and bHR rats in multiple tests over a period of days to weeks. These prior studies demonstrated that bLR/bHR rats (a) exhibit reliable behavioral differences across several behavior tests and (b) behave consistently on a particular test (such as the EPM) whether they are exposed only to that single test, or subjected to it after completing a series of other behavior tests over time (Clinton et al., 2014). It took approximately 10 days to complete this test battery, so rats were $\mathrm{P} 85$ on the final test day.

Forced Swim Test (FST)—Porsolt's FST was performed as described by Cryan et al. (Cryan et al., 2005) in a Plexiglas cylinder (40 $\mathrm{cm}$ high $\times 40 \mathrm{~cm}$ diameter) containing $30-\mathrm{cm}$ deep water $\left(25^{\circ} \mathrm{C}\right)$. On FST day 1, rats were placed (one rat/cylinder) in the water for 15$\min$ (pretest phase); $24 \mathrm{~h}$ later the rats were returned to the water-filled cylinder and videotaped for 5-min (test phase). Water was changed after every swim session so that each rat swam in clean water. A trained observer blind to treatment scored the FST immobility (floating) time using a computer program for ethological analysis (Observer, Noldus, Wageningen, The Netherlands). Rats were considered immobile when they exhibited no activity other than that required to keep their heads above water. We chose to focus on the immobility measure since it is classically considered an indicator of "behavioral despair" and depression-like behavior (Porsolt et al., 1977), and it can be clearly defined and easily distinguishable from active coping measures such as swimming and climbing, which are sometimes difficult to reliably distinguish across experimental observers (Porsolt et al., 1977, Cryan et al., 2005, Muigg et al., 2007). Data are presented as time immobile as percent of total time during the 5-min Day 2 test.

Open Field Test-The Open field apparatus is a $100 \times 100 \times 50 \mathrm{~cm}$ white Plexiglas box with a black floor. The periphery was defined by a $20-\mathrm{cm}$ zone around the edge of the apparatus, and the center zone was therefore defined as a $60 \times 60 \mathrm{~cm}$ zone in the middle of the apparatus. The peripheral area was further subdivided into the corners $(20 \times 20 \mathrm{~cm}$ areas at each of the four corners) and remaining space was considered the sides of the apparatus. At the beginning of each test, an animal was placed in the corner of the open field and behavior was recorded for $5 \mathrm{~min}$. Testing was conducted under dim light (30 lux) between 8:00-11:30 am, and a computerized behavior analysis program (Ethovision, Noldus, Wageningen, The Netherlands) recorded the latency to enter the center of the open field, the 
amount of time spent in the center, sides, and corner of the apparatus, and the total distance traveled during the 5-min test.

Elevated Plus Maze (EPM)-The EPM is constructed of black Plexiglas with four elevated arms ( $70 \mathrm{~cm}$ from the floor, $45 \mathrm{~cm}$ long, $12 \mathrm{~cm}$ wide) arranged in a cross. Two opposite arms are enclosed by 45-cm-high walls (lighting approximately 3-5 lux), and the remaining two arms are open (lighting approximately 30 lux). To start the test rats were placed in a central square platform facing the same closed arm at the intersection of the open and closed arms provided access to all arms. Testing was conducted under dim light (30 lux) between 8:00-11:30 am, and recorded using the Ethovision videotracking system to assess the latency to enter the open arms, the amount of time spent in the open arms, closed arms, and center square, and the total distance traveled over the course of the 5-min test. An animal was considered to be in the open arm when the rat's body fully crossed out of the center square onto an open arm platform.

Locomotor Response to Novelty-In Experiment 1, behavioral response to novelty was assessed based on distance traveled in the Open Field test since the adult males had already been screened for novelty-induced locomotion in our standard test apparatus. In Experiment 2, perinatal paroxetine- and vehicle-exposed offspring were tested for noveltyinduced locomotion using our previously published protocol (Stead et al., 2006a). Briefly, rats were individually placed in standard clear acrylic cages $(43 \times 21.5 \times 25.5 \mathrm{~cm}$ high) equipped with infrared photocell emitters mounted $2.3-$ and $6.5-\mathrm{cm}$ above the floor to record horizontal and rearing movement. The test chambers were located in a behavioral testing room separate from the housing quarters, and the rats were exposed to the test chamber for the first time on the day of testing. Horizontal and rearing movements were monitored in 5min intervals over a period of 60-min via computer. Novelty-induced locomotor scores for each rat were calculated by adding the total number of horizontal and rearing movements over the 60-min test period.

\subsection{Tissue collection, preparation and genome-wide expression profiling}

Genome-wide expression profiling experiments were performed and analyzed in a manner similar to our previous microarray studies (Stead et al., 2006; Clinton et al., 2011). Perinatal paroxetine- and vehicle-exposed bLR male offspring were sacrificed by rapid decapitation at $\mathrm{P} 7, \mathrm{P} 14, \mathrm{P} 21$, and P75 ( $\mathrm{n}=5$ per treatment per time point, with each group being comprised of animals from 5 independent litters). Brains were removed, flash frozen, and stored at $-80^{\circ} \mathrm{C}$ until further processing. Brain tissue punches were collected as we previously described (Simmons et al., 2013). Brains were sectioned in a cryostat between -10 and $-12^{\circ} \mathrm{C}$, with alternating sections of $20 \mu \mathrm{m}$ and $300 \mu \mathrm{m}$ collected. The $20 \mu \mathrm{m}$ sections were cresyl violet-stained to identify appropriate anatomical regions in the corresponding $300 \mu \mathrm{m}$ sections. Samples from the hippocampus and amygdala were removed from the thick sections using a $0.5 \mathrm{~mm}$ tissue punch (Harris Micro-Punch, Ted Pella, Redding, CA), placed in RNAlater (Qiagen, Valencia, CA), and stored at $-20^{\circ} \mathrm{C}$.

Tissue punches were shipped on dry ice for microarray processing on NimbleGen Rat Gene Expression 12x135K Arrays (26,419 target genes, 5 probes/target; Arraystar, Rockville, 
MD). RNA was isolated and purified using the TRIzol method. Briefly, tissue was homogenized in TRIzol (Life Technologies) and incubated at room temperature to allow dissociation of nucleoproteins. Chloroform was then added to each homogenized sample and centrifuged at $12,000 \mathrm{~g}$ for $15 \mathrm{~min}$ at $4^{\circ} \mathrm{C}$. Next, RNA was precipitated with isopropyl alcohol and spun down at $12,000 \mathrm{~g}$ for $10 \mathrm{~min}$ at $4{ }^{\circ} \mathrm{C}$. The pellet was washed in ethanol, allowed to air dry, and resuspended in $100 \mu \mathrm{LEPC}-\mathrm{H}_{2} \mathrm{O}$. RNA quantity and quality were measured by NanoDrop ND-1000; RNA integrity was assessed by standard denaturing agarose gel electrophoresis.

RNA labeling and array hybridization-Total RNA from each sample was linearly amplified with Agilent's Low Input Quick Amp Kit (Agilent Technology). Double-stranded cDNA (ds-cDNA) was synthesized from the amplified cRNA using an Invitrogen SuperScript ds-cDNA synthesis kit in the presence of 100pmol oligo dT primers. ds-cDNA was cleaned and labeled in accordance with the NimbleGen Gene Expression Analysis protocol (NimbleGen Systems, Inc., USA). Briefly, ds-cDNA was incubated with $4 \mu \mathrm{g}$ RNase A at $37^{\circ} \mathrm{C}$ for 10 min and cleaned using phenol:chloroform:isoamyl alcohol, followed by ice-cold absolute ethanol precipitation. The purified cDNA was quantified using a NanoDrop ND-1000. For Cy3 labeling of cDNA, the NimbleGen One-Color DNA labeling kit was used according to the manufacturer's guideline detailed in the Gene Expression Analysis protocol (NimbleGen Systems, Inc., Madison, WI, USA). One microgram of ds-cDNA was incubated for $10 \mathrm{~min}$ at $98^{\circ} \mathrm{C}$ with $1 \mathrm{OD}$ of Cy3-9mer primer. Then, 100pmol of deoxynucleoside triphosphates and 100U of the Klenow fragment (New England Biolabs, USA) were added and the mix incubated at $37^{\circ} \mathrm{C}$ for 2 hours. The reaction was stopped by adding 0.1 volume of $0.5 \mathrm{M}$ EDTA, and the labeled ds-cDNA was purified by isopropanol/ethanol precipitation. Microarrays were hybridized at $42^{\circ} \mathrm{C} 16-20 \mathrm{~h}$ with $4 \mu \mathrm{g}$ of Cy3 labeled ds-cDNA in NimbleGen hybridization buffer/hybridization component A in a hybridization chamber (Hybridization System - NimbleGen Systems, Inc., Madison, WI, USA). Following hybridization, washing was performed using the NimbleGen Wash Buffer kit (NimbleGen Systems, Inc., Madison, WI, USA). After being washed in an ozone-free environment, the slides were scanned using the Axon GenePix 4000B microarray scanner.

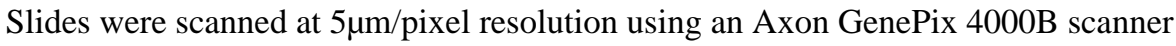
(Molecular Devices Corporation) piloted by GenePix Pro 6.0 software (Axon). Scanned images (TIFF format) were imported into NimbleScan software (version 2.5) for grid alignment and expression data analysis. Expression data were normalized through quantile normalization and the Robust Multichip Average (RMA) algorithm included in the NimbleScan software. The Probe level files and Gene level files were generated after normalization.

Microarray analysis-All gene level files were imported into Agilent GeneSpring GX software (version 12.6) for further analysis. Probes with a raw expression value less than 50 for any sample were excluded from the analysis. The samples were then filtered to exclude any probes designated "predicted mRNA model", as determined by the most recent RefSeq database annotations. Following experimental grouping (i.e., perinatal SSRI- versus vehicleexposed bLR at a particular developmental time point and specific brain region), differentially expressed genes with statistical significance were identified through volcano 
plot filtering, using cutoffs of fold change $>1.5$, p-value $<0.05$ [Bonferroni family-wise error rate (FWER)]. Venn diagrams were created from the resulting probe lists.

Probe lists were selected for k-means partitional clustering if they passed volcano plot filtering in the P75 comparison. Based on this criterion, 80 differentially expressed genes (perinatal SSRI- versus vehicle-exposed groups) from the amygdala were assigned to 6 clusters, while 360 differentially expressed genes from the hippocampus were assigned to 10 clusters. The differential distance metric, which categorizes genes based on the slope across time points, was used to assign the differentially expressed genes to clusters with the goal of increasing similarity of genes within clusters, while decreasing similarity between clusters. Gene Ontology (GO) analysis was used to identify enrichment of functionally-related genes within each cluster, using a p-value cutoff of 0.05. All genes and transcripts discussed in this paper are referenced by the Rattus norvegicus gene symbol.

\subsection{Statistical analysis}

Statistical analyses were performed using SPSS (IBM). In Experiment 1, we used 2-way ANOVA (bHR/bLR phenotype $\times$ paroxetine treatment as independent variables) and behavioral measures as dependent variables. In Experiment 2, we used 2-way ANOVA (bHR/bLR phenotype $\times$ paroxetine treatment as independent variables) and pregnancy measures (dams' weight gain, number of pups) as dependent variables. Maternal behavior data was analyzed using repeated measures two-way ANOVA (maternal bHR/bLR phenotype $\times$ paroxetine treatment independent variables and first versus second postnatal week as repeated measure). Data were separately analyzed for the light versus dark phase. Our behavioral assessment of the paroxetine- and vehicle-exposed offspring examined experimental groups comprised of 3 males per litter. To control for possible "litter effects," data from 3 littermates were averaged before further statistical analyses. Thus, we analyzed $\mathrm{n}=8$ litters/treatment/phenotype, with 24 animals represented within each of the 4 groups. We used 2-way ANOVA (bHR/bLR phenotype $\times$ perinatal paroxetine exposure) as independent variables and behavioral measures as dependent variables. When appropriate, Tukey's post hoc tests were applied with necessary corrections for multiple comparisons. Paroxetine drug levels were compared in adult bHR/bLR drug-exposed rats' blood and brain tissue by unpaired Student's t-test. Data are presented as mean \pm SEM and for all tests $a=0.05$. Data analysis methods for the Experiment 3 microarray study are noted above.

\section{Results}

\subsection{Chronic paroxetine treatment during adulthood reduced bLRs' depression-like behavior, but had minimal effect on novelty-induced activity and anxiety-like behavior}

In Experiment 1, adult male bHR/bLR rats were chronically treated with the SSRI paroxetine to assess its effect on depression-like behavior (immobility) in the FST and anxiety-like behaviors (Fig. 1A shows a timeline for drug treatment and behavioral testing). Adult bLR males generally exhibited far greater immobility/floating compared to bHR males (main effect of phenotype $F_{(1,44)}=44.09, p<0.001$; Fig. 1B). Although there was no main effect of paroxetine treatment on FST immobility, there was a phenotype x paroxetine interaction $\left(F_{(1,44)}=9.78, p=0.003\right)$. Post hoc analysis showed that chronic paroxetine 
treatment specifically reduced bLRs' FST immobility compared to vehicle-treated bLRs $(\mathrm{p}=0.017)$; bHR FST performance was unaffected by paroxetine treatment (Fig. 1B).

As expected, there were robust bHR/bLR behavioral differences in the open field test, with bHRs showing greater novelty-induced locomotor activity compared to bLRs (main effect of phenotype $F_{(1,44)}=214.74, p<0.001$ on total distance traveled; Fig. 1C). There was no effect of paroxetine treatment on locomotor activity, and no phenotype $\mathrm{x}$ paroxetine interaction. bLRs generally exhibited greater anxiety-like behavior than bHRs, spending less time in the center of the open field (main effect of phenotype $F_{(1,44)}=49.30, p<0.001$; bHR-vehicle rats spent $8.0 \%$ time in the center $\pm 0.9 \%$; bHR-paroxetine rats spent $6.0 \%$ time in the center $\pm 0.9 \%$; bLR-vehicle animals spent $1.8 \%$ time in center $\pm 0.6 \%$; bLR-paroxetine animals spent $0.9 \%$ time in center $\pm 0.3 \%$ ). There was no effect of paroxetine treatment on time spent in the center, and no phenotype x paroxetine interaction. For the initial latency to enter the center of the open field, there was no effect of phenotype or paroxetine, and no phenotype x paroxetine interaction.

In the EPM, bLRs generally exhibited more anxiety-like behavior than bHRs, spending less time in the open arms (main effect of phenotype $F_{(1,44)}=14.11, p<0.001$; Fig. 1D) and greater latency to initially enter the open arms (main effect of phenotype $F_{(1,44)}=3.57, p=$ 0.049; average latencies to open arm for each group: bLR-vehicle, $101 \pm 35 \mathrm{sec}$; bLRparoxetine, $84 \pm 37 \mathrm{sec}$; bHR-vehicle, $20 \pm 5 \mathrm{sec}$; and bHR-paroxetine, $28 \pm 11 \mathrm{sec}$ ). The bLR rats also displayed greater stress-induced defecation than bHRs (main effect of phenotype $F_{(1,44)}=8.47, \mathrm{p}<0.001 ;$ Fig. 1E). There was no effect of paroxetine treatment and no phenotype $\mathrm{x}$ paroxetine interaction for either measure.

\subsection{Effects of paroxetine treatment on bHR/bLR female rats pregnancy and maternal behavior}

The bHR/bLR females were treated with paroxetine (or vehicle) throughout the mating period, pregnancy and the 3-week postpartum period. The following data are from the first cohort of rats in Experiment 1 ( $\mathrm{n}=4$ dams/condition). Paroxetine treatment significantly lengthened the time to conception in both bHR and bLR females, with drug-treated females taking twice as long to conceive compared to vehicle-treated females (main effect of paroxetine treatment, $F_{(1,14)}=4.24, p=0.05$; average latencies to conceive for each group: bLR-vehicle, $2.0 \pm 0.4$ days; bHR-vehicle, $2.0 \pm 0.3$ days; bLR-paroxetine, $7.0 \pm 3.6$ days; and bHR-paroxetine, $4.6 \pm 2.2$ days). There was no effect of bHR/bLR phenotype on time to conceive, and no paroxetine x phenotype interaction. Once animals became pregnant, we observed a similar pattern of weight gain across groups (no effects of paroxetine treatment, phenotype, and no drug x phenotype interaction). Paroxetine treatment did reduce litter size, with paroxetine-treated dams having slightly but significantly smaller litters compared to vehicle-treated dams (main effect of drug treatment $F_{(1,14)}=8.1, p=0.013$; average litter sizes for each group: bLR-vehicle, $15 \pm 1$ pups; bHR-vehicle, $17 \pm 1$ pups; bLR-paroxetine, $11 \pm 2$ pups; and bHR-paroxetine, $13 \pm 1$ pups). There was no effect of bHR/bLR phenotype on litter size, and no drug x phenotype interaction. Pups' birth weight did not differ between treatment groups. Further, there was no effect of phenotype or treatment and no phenotype $x$ treatment interaction on maternal water/liquid intake. Furthermore, there was no phenotypic 
difference in paroxetine intake (averaged daily paroxetine intake for bHR was $2.83 \pm 0.33$ $\mathrm{mg}$; bLR, $2.73 \pm 0.23 \mathrm{mg}$ ).

We monitored behavior in paroxetine- and vehicle-treated bHR/bLR dams from P1-14 to determine whether paroxetine treatment affected their maternal behavior ( $\mathrm{n}=5-13 \mathrm{dams}$ / condition). Figure 2 shows the amount of licking/grooming (Fig. 2A-B), arched-back nursing (Fig. 2C-D), passive nursing (Fig. 2E-F), and resting behavior (Fig. 2G-H) that paroxetine- and vehicle-treated $\mathrm{bHR} / \mathrm{bLR}$ dams displayed during the first two postpartum weeks. All dams generally displayed more licking/grooming behavior during the first postnatal week compared to the second during the light phase (main effect of postnatal week $\left.F_{(1,37)}=17.235, p<0.001\right)$, but there was no effect of postnatal week for the dark phase. There was no effect of paroxetine treatment, no effect of bHR/bLR phenotype, and no significant drug $\times$ phenotype interaction for licking/grooming in the light phase, but there was a postnatal week x paroxetine interaction in the dark phase $\left(F_{(1,37)}=9.059, p=0.005\right.$; Fig. 2A-B). A similar pattern was observed for arched-back nursing, with all dams generally showing more arched-back nursing during the first versus second postnatal week in the light phase (main effect of postnatal week $F_{(1,37)}=141.731, p<0.001$ ) and in the dark phase (main effect of postnatal week $\left.F_{(1,37)}=14.201, p=0.001\right)$. We found that bLR mothers spent more time arched-back nursing their pups during the dark phase compared to bHR dams (main effect of phenotype $F_{(1,37)}=4.952, p=0.032$ ). There was no effect of paroxetine treatment on arched-back nursing in either the light phase or dark phase, and no significant drug $\times$ phenotype interactions (Fig. 2C-D). Most dams showed a dramatic increase in the amount of passive nursing from postnatal week one to two during the light phase (main effect of postnatal week $F_{(1,37)}=51.986, p<0.001$ ) and the dark phase (main effect of postnatal week $\left.F_{(1,37)}=23.666, p<0.001\right)$. bLR versus bHR mothers exhibited significantly less passive nursing during the light phase (main effect of phenotype $F_{(1,37)}=$ $5.310, p=0.027)$. There was no effect of paroxetine treatment on passive nursing during the light phase, although there was a significant postnatal week x phenotype interaction $\left(F_{(1,37)}\right.$ $=4.631, p=0.038$ ). Post-hoc analysis showed that bLR dams were specifically affected by paroxetine treatment, with paroxetine-treated dams showing dramatically less passive nursing compared to vehicle-exposed LR dams $(p=0.007)$. The bHR dams behaved similarly in drug- and vehicle-treated conditions. There were no effects of paroxetine treatment or phenotype on passive nursing in the dark phase, and there were no significant interactions (Fig. 2E-F). We found that dams generally spent more time resting during the second versus first postnatal week in the light phase (main effect of postnatal week $F_{(1,37)}=$ $41.95, p<0.001$ ) and in the dark phase (main effect of postnatal week $F_{(1,37)}=7.577, p=$ 0.009). Interestingly, paroxetine-treated dams spent more time resting compared to vehicletreated dams during the light phase (main effect of paroxetine treatment $F_{(1,37)}=32.934, p<$ 0.001 ) and during the dark phase (main effect of paroxetine treatment $F_{(1,37)}=20.77, p<$ 0.001). In general, bLRs versus. bHRs spent more time resting during the dark phase (main effect of phenotype $\left.F_{(1,37)}=18.67, p=0.001\right)$. During the light phase there was no effect of $\mathrm{bHR} / \mathrm{bLR}$ phenotype and there were no significant interactions during the light or dark phases (Fig. 2G-H). 


\subsection{Confirming paroxetine levels in drug-exposed rats}

We measured paroxetine levels in the blood and brains of adult bHR/bLR males that were chronically treated with paroxetine. We found similar drug levels in the serum of bHR and bLR rats (bHR: $160.5 \pm 84.64 \mathrm{ng} / \mathrm{ml}$; bLR: $136.40 \pm 64.03 \mathrm{ng} / \mathrm{ml}$ ) and in the brain (bHR: $2.19 \pm 1.08 \mu \mathrm{g} / \mathrm{g}$; bLR: $1.75 \pm 0.83 \mu \mathrm{g} / \mathrm{g}$ ). We also assessed paroxetine levels in brain tissue collected from P7 bLR pups during the Experiment 3 microarray study. We found that average paroxetine concentration in P7 pups' brain tissue was $0.28 \pm 0.08 \mu \mathrm{g} / \mathrm{g}$.

\subsection{Perinatal paroxetine exposure worsened bLR offspring's adult depression-like behavior, but did not affect behavior in bHR offspring}

Adult bHR/bLR offspring that were perinatally-exposed to paroxetine or vehicle treatment throughout gestation and the lactation period were examined in three behavioral tests (Fig. $3 \mathrm{~A}$ depicts the experimental timeline). As before, bLRs generally exhibited higher FST immobility compared to bHRs (main effect of phenotype $F_{(1,28)}=90.81, p<0.001$; Fig. 3B). There was also a main effect of paroxetine treatment $\left(F_{(1,28)}=9.972, p=0.004\right)$ and a paroxetine $\mathrm{x}$ phenotype interaction $\left(F_{(1,28)}=6.720, p=0.015\right)$. Post hoc analysis showed that bLRs exposed to perinatal paroxetine exhibited greater FST immobility compared to vehicle-exposed bLRs $(p=0.002)$ while bHR offspring's FST performance was not affected by early-life paroxetine exposure (Fig. 3B).

Perinatal paroxetine exposure did not impact locomotor response to novelty in either strain; bHRs remained more exploratory than bLRs (main effect of phenotype $F_{(1,28)}=331.4, p<$ 0.001 ; Fig. $3 \mathrm{C}$ ). There was no effect of perinatal paroxetine on locomotor response to novelty and no drug $\mathrm{x}$ phenotype interaction. Likewise, perinatal paroxetine exposure did not affect EPM behavior. bHRs generally showed less anxiety-like behavior compared to bLRs, spending more time in the open arms (main effect of phenotype $F_{(1,28)}=31.19, p<$ 0.001; Fig. 3D) and less stress-induced defecation in the EPM (main effect of phenotype $F_{(1,28)}=33.61, p<0.001$; Fig. 3E). There was no effect of neonatal paroxetine exposure on any of these measures and no paroxetine $\mathrm{x}$ phenotype interactions, suggesting that paroxetine has minimal effect on bHR/bLR anxiety-like behavior in the EPM, at least under our described test conditions.

\subsection{Effect of perinatal paroxetine exposure on developmental gene expression patterns in bLR brain regions}

Microarray studies focused on bLR offspring since the behavioral experiment demonstrated that they were selectively susceptible to the effects of perinatal SSRI exposure on behavior while bHRs were unaffected. Volcano plot filtering of the genome-wide expression data (fold change $>1.5, \mathrm{p}<0.05$, Bonferroni FWER) revealed robust developmental gene expression changes in male bLR offspring perinatally-exposed to paroxetine (versus vehicle) within both the amygdala (Fig. 4A) and hippocampus (Fig. 4B). In the P7 amygdala, only 3 genes were significantly changed in perinatal SSRI- versus vehicle-treated bLR offspring, with all of those genes being up-regulated. In the amygdala of paroxetine-exposed bLRs, the number of significantly regulated genes ranged from a low of 3 (P7) to a high of 187 (P21), declining to 80 genes by adulthood (P75) (Fig. 4C, black triangles). Of those differentially expressed transcripts in the developing amygdala, the majority of the genes were down- 
regulated at P14, P21, and P75 (Fig. 4D). In the P7 hippocampus, 722 genes were differentially expressed in bLR offspring that were exposed to perinatal paroxetine versus vehicle. The number of genes altered in the bLR hippocampus following perinatal SSRI exposure dropped to 80 genes by P21, but then increased to 360 genes by P75 (Fig. 4C, white triangles). The vast majority of differentially expressed genes were down-regulated at P7 and P14; however, by P75 almost all of the differentially expressed genes were upregulated (Fig. 4E).

We reasoned that genes differentially expressed following perinatal paroxetine exposure across multiple time points and/or across multiple brain regions were likely to be biologically significant; we therefore generated Venn diagrams to demonstrate the number of genes that were altered by perinatal SSRI exposure either $a$ ) throughout development or $b$ ) in both amygdala and hippocampus (Fig. 5). We found little overlap in groups of perinatal SSRI-altered genes between developmental ages in the amygdala, with the greatest overlap of 32 genes at P14 and P21 (Fig. 5A). In the hippocampus, the greatest overlap between ages was between P7 and P14 (145 overlapping genes), followed by P7 and P75 (105 overlapping genes). A set of 57 genes was altered by perinatal SSRI exposure in the P7, P14, and P75 hippocampus; this group of genes included transcripts for several synaptic vesicle-associated proteins (Fig. 5B). When comparing groups of perinatal SSRI-altered genes across the hippocampus and amygdala, there was surprisingly minimal overlap in the two data sets, with no overlap at P7, 2 overlapping genes at P14, 12 genes at P21, and 13 genes at P75 (Fig. 5C).

Although simplistic, it is reasonable to assume that genes exhibiting similar developmental expression profiles may be functionally related. We therefore used partitional clustering examine the hippocampus and amygdala gene expression data sets, grouping perinatal paroxetine-altered genes within each brain region based on their developmental expression patterns. Partitional clustering of the 80 genes in the P75 amygdala data set assigned genes to one of six clusters based on the slope of the expression pattern of each gene across time (differential distance metric), shown in Figure 6. Each of the six clusters displays the normalized expression values of genes at 3 early developmental time points (P7, P14, P21) when the offspring were still being exposed to paroxetine via their mothers' milk and P75 when perinatal paroxetine-induced behavioral deficits were apparent in adult bLR offspring in Experiment 2. GO analysis was used to identify functionally related genes within the six gene clusters and found significant enrichment in GO terms for clusters 4 (GO:0005833, hemoglobin complex; $p=0.0000504)$ and 5 (GO:0043229, intracellular organelle; $p=$ 0.033 ) (Fig. 6). Similar partitional clustering and GO analysis was used to evaluate the 360 perinatal SSRI-altered genes in the P75 hippocampus; this revealed ten gene clusters (Figure 7). GO analysis found significant enrichment for specific GO terms for cluster 2 ( $G O$ : 0003735-GO:0003742, structural constituent of ribosome; $p=4.81 \times 10^{-13}$ ), cluster 3 (GO:0016676, oxidoreductase activity, acting on a heme group of donors, oxygen as acceptor; $p=0.05)$, cluster 4 (GO:0008021, synaptic vesicle; $p=0.034)$, cluster 6 (GO: 0033673, negative regulation of kinase activity; $p=0.039$ ), and cluster 7 (GO:0022008, neurogenesis; $p=0.006$ ) (Fig. 7). 


\section{Discussion}

Given the widespread use of SSRIs in pregnant and nursing women and limited knowledge of the long-term, potentially adverse effects of these medications on exposed children (Oberlander et al., 2010, Croen, 2011, Klinger et al., 2011), it is imperative to examine how these medications impact brain development and behavior in susceptible individuals. Rodent studies point to significant life-long biobehavioral abnormalities following perinatal SSRI exposure, including increased depression-like behavior in adulthood (Ansorge et al., 2004, Olivier et al., 2011) and aberrant 5-HT circuit formation (Kinney et al., 1997, Maciag et al., 2006a, Weaver et al., 2010). Our present results demonstrate individual differences in susceptibility to neonatal early-life exposure to the SSRI paroxetine, with rats genetically predisposed to a highly inhibited, high anxiety/depression-like phenotype (bLR) being vulnerable to the perinatal paroxetine-induced behavioral effects (exaggerating their already high levels of FST immobility), while risk-taking/aggressive (bHR) rats were resistant. Genome-wide expression profiling revealed robust, region-specific gene expression differences in the developing brain of the "paroxetine susceptible" bLR rats following perinatal paroxetine exposure (gestation through weaning). The vast perinatal paroxetineinduced gene expression differences point to multiple molecular changes, including drugelicited alterations of mitochondrial function, synaptic vesicle transport/release, and neurogenesis, which may trigger long-term behavioral abnormalities (i.e., increased adult FST immobility and other depression-like measures) associated with perinatal paroxetine exposure.

\subsection{Individual differences in susceptibility to behavioral effects to perinatal SSRI exposure}

Although several prior rodent studies report increased anxiety- and/or depression-like behavior following perinatal SSRI and tricyclic antidepressant exposure, results have been inconsistent. Several studies found that early-life SSRI or tricyclic antidepressant exposure leads to increased FST immobility in adulthood (Hilakivi and Hilakivi, 1987, Hilakivi et al., 1988, Velazquez-Moctezuma and Diaz Ruiz, 1992, Hansen et al., 1997, Vazquez-Palacios et al., 2005), but other studies did not observe this effect (Yoo et al., 2000, Maciag et al., 2006b, Lisboa et al., 2007). Our results suggest that such inconsistencies are due to naturally-occurring emotionality differences among experimental animals that may convey distinct susceptibility (or resistance) to perinatal antidepressant exposure. The phenomenon of individual differences in emotional behavior is well-known (Piazza et al., 1989, Frankova and Mikulecka, 1990, Landgraf and Wigger, 2002, Kabbaj, 2004, Veenema et al., 2007, Bosch, 2011, Flagel et al., 2014). Many behavioral traits exist in a spectrum, with some individuals expressing high, medium, or low levels of a given characteristic. Moreover, certain behavioral traits can predict a constellation of other behavioral attributes. For instance, individual differences in novelty reactivity predict several other behaviors, including response to psychostimulants (Piazza et al., 1989), hypothalamic adrenal axis stress reactivity (Piazza et al., 1993, Kabbaj et al., 2000, Marquez et al., 2006), anxiety- and depression-like behavior (Kabbaj, 2004, Stead et al., 2006a, White et al., 2007, Jama et al., 2008, Blanchard et al., 2009, Garcia-Fuster et al., 2011, Stedenfeld et al., 2011, Clinton et al., 2014) [for review see (Flagel et al., 2014)]. Our current data suggest that the high versus low novelty seeking traits also predict vulnerability to early-life antidepressant exposure. 
Thus, in previous perinatal antidepressant exposure studies, experimental groups may have included a mix of animals with more high novelty responding (bHR)-like or low noveltyreactive (bLR)-like tendencies. Experimental groups that inadvertently included a high proportion of perinatal antidepressant-resistant/bHR-like rats might have found limited behavioral abnormalities in response to neonatal antidepressant exposure, while cohorts that included more perinatal antidepressant susceptible/bLR-like rats might have found strong effects. Our findings may also indicate possible reasons why human individuals respond differently to perinatal antidepressant exposure. For example, Klinger et al. 2011 reported increased social behavior abnormalities in children ages 4-6 who were exposed to SSRIs during gestation and showed signs of antidepressant withdrawal at birth; however, SSRIexposed children that showed no signs of antidepressant withdrawal as infants exhibited normal social behavior at ages 4-6. Similarly, there are conflicting reports of the association between perinatal SSRI exposure and risk of autism (Croen, 2011, Harrington et al., 2013, Rai, 2013, Clements et al., 2014). Together these studies indicate that both humans and experimental animals exhibit individual differences in susceptibility to the effects of earlylife antidepressant exposure.

There are mixed reports on the effects of early-life antidepressant exposure on anxiety-like behavior and locomotor activity in rodents. Neonatal exposure to SSRIs fluoxetine and citalopram increased adult offspring's anxiety-like behavior in multiple tests (Ansorge et al., 2008). Likewise, perinatal exposure to the tricyclic clomipramine (Andersen et al., 2010) and the SSRI fluoxetine (Noorlander et al., 2008) increased anxiety in the EPM, although other groups found no effect of neonatal citalopram (Harris et al., 2012) fluoxetine (Lisboa et al., 2007, Lee and Lee, 2012), or escitalopram (Bourke et al., 2013b). Other work reported that early-life citalopram exposure enhanced adult locomotor activity (Maciag et al., 2006a, Maciag et al., 2006b), while others found the opposite effect (Ansorge et al., 2008, Noorlander et al., 2008, Lee and Lee, 2012). We found that early-life paroxetine exposure did not affect bHR/bLR novelty-induced locomotor activity or EPM performance. The effects of early-life antidepressant exposure on anxiety and locomotor activity may depend upon the specific drug (i.e., tricyclic versus SSRI or even disparate effects of different types of SSRIs, more on this in Section 4.5). Behavioral effects may also be species- or straindependent, since various studies on this topic have been conducted in multiple strains of mice and rats. Alternatively, considering bLR rats' typically high levels of spontaneous anxiety-like behavior (i.e., spending little time in the center of the Open Field and open arms of the EPM), there may be a ceiling effect that obscures our ability to see any exacerbation of bLRs' anxiety following early-life paroxetine exposure. Modifying of our test conditions (or perhaps using another anxiety test) may have offered a milder anxiogenic stimulus that could potentially reveal an effect of perinatal SSRI exposure on bLRs' anxiety-like behavior. It is also important to keep in mind that there is a strong genetic underpinning of the bLR phenotype, so behavior such as locomotor response to novelty (which has been selectively bred over dozens of generations) may be so genetically entrenched that it is difficult to shift via environmental factors. In general, it would be interesting to expand this work to determine what other behavioral deficits (e.g., sexual behavior, sleep, aggression, anhedonia-all previously shown to be affected by perinatal SSRI exposure) arise in bLR 
animals following early-life exposure to paroxetine or other SSRIs, and whether bHRs would continue to be resistant to those effects.

The observed differences in bLR versus bHR vulnerability to perinatal SSRI exposure may be linked to 5-HT circuit differences. For instance, compared to bHRs, adult bLR rats exhibit lower Tph2, Sert (Kerman et al., 2011) and 5ht1 a receptor (Calvo et al., 2011) mRNA in the dorsal raphe, and increased 5htla (Clinton et al., 2011a), 5ht2a (Calvo et al., 2011), 5ht6 and 5 ht7 (Ballaz et al., 2007b) receptor mRNA in multiple limbic regions. Pharmacological studies suggest that these 5-HTergic differences shape aspects of the disparate bHR/bLR behavioral phenotypes, including their differences in social interaction (Calvo et al., 2011, Cummings et al., 2013), aggression (Kerman et al., 2011), cognition (Ballaz et al., 2007a), reward-processing (Capriles et al., 2012), and anxiety-like behavior (Verheij et al., 2009). Such differences could be related to distinct SERT polymorphisms (as noted in humans (Oberlander et al., 2008a, Oberlander et al., 2010), and may contribute to their distinct responses to early-life SSRI exposure. Additional experiments will be required to investigate these possibilities.

\subsection{Neurobiological consequences of perinatal SSRI exposure in the developing amygdala versus hippocampus}

While neonatal exposure to tricyclic (Feenstra et al., 1996, Kinney et al., 1997, Vijayakumar and Meti, 1999) and SSRI (Maciag et al., 2006a, Weaver et al., 2010, Simpson et al., 2011) antidepressants causes lasting 5-HTergic circuit malformation, surprisingly little is known about the accompanying neural changes that trigger its effects on emotional behavior. Neonatal citalopram exposure increased firing of noradrenergic neurons in the locus coeruleus (Darling et al., 2011), increased noradrenergic fiber density in the neocortex (Zhang et al., 2011), and perturbed axon myelination in the corpus callosum (Simpson et al., 2011). One recent study showed that early postnatal fluoxetine exposure induces long-term up-regulation of histone deacetylase 4 (Hdac4) mRNA in the hippocampus of adult drugexposed offspring (Sarkar et al., 2014), and another found minimal hippocampal and amygdalar gene expression changes in adult offspring that were exposed to escitalopram in early life (Bourke et al., 2013b). Importantly, the majority of this work focused on neurobiological changes in the adult brain following perinatal antidepressant exposure with no studies examining drug-induced alterations in developing brains during the period of drug exposure. This knowledge gap motivated the current genome-wide expression study where we examined widespread gene expression changes in the developing (P7, P14, P21) and adult (P75) hippocampus and amygdala of offspring that were perinatally exposed to the SSRI paroxetine.

We focused our analysis on brains of bLR animals, since our behavioral studies showed that they were susceptible to perinatal paroxetine-induced behavioral abnormalities while bHRs were resistant. Moreover, we selected three early developmental time points when early-life paroxetine exposure was ongoing (P7, P14, and P21) as well as an adult time point (P75), long after drug-exposure ceased but behavioral abnormalities appeared. Another reason for choosing these three early time points (P7, P14, P21) was that the first three postnatal weeks represent a critical developmental period for rodent neural systems, evident in radical 
changes in behavior, neuroendocrine response, synaptic connectivity, and global neural gene expression (Sapolsky and Meaney, 1986, Eilam and Golani, 1988, Stead et al., 2006b). These time points are also consistent with other related studies by our research group examining developmental gene expression pattern differences in bHR/bLR rats at baseline (Clinton et al., 2011b) and following early-life environmental manipulations such as crossfostering bLR pups to bHR mothers (Cohen, Glover, Clinton et al, In Revision 2014). By using consistent time points across developmental gene expression studies, we can evaluate how changes in the developing brain are evoked by disparate environmental factors (i.e., early-life paroxetine exposure in the present study, cross-fostering in another), how different brain areas are affected, and how the timing of changes may differ depending on the type of stimulus.

Early-life paroxetine exposure elicited distinct gene expression patterns in the developing bLR amygdala versus hippocampus. Perinatal paroxetine exposure did not substantially alter bLRs' amygdalar transcriptome until the second and third postnatal weeks, with approximately 200 genes altered in the P14 and P21 amygdala of drug-exposed bLRs versus. vehicle-exposed pups. Conversely, early-life paroxetine exposure dramatically altered gene expression in the developing hippocampus with more than 700 genes altered at P7, 300 genes altered at P14, and 150 genes altered at P21. By adulthood, drug-induced gene expression changes remain more pronounced in the hippocampus versus amygdala (400 altered genes in the hippocampus versus. 150 genes in the amygdala), suggesting that the hippocampus may be more sensitive to the effects of early-life paroxetine than the amygdala.

Multiple factors may contribute to the distinct effects of perinatal paroxetine exposure on the hippocampus versus amygdala, including the ontogeny of the dorsal raphe and other 5HTergic nuclei that innervate these regions and developmental expression of 5-HT receptors in the hippocampus and amygdala. Dorsal and caudal portions of the dorsal raphe as well as the median raphe provide the major source of 5-HT to the hippocampus, amygdala, and other limbic regions (Lowry et al., 2008). Most of these 5-HT cells are born between embryonic day 10-12 (Cordes, 2005), although 5-HTergic innervation develops over a period of weeks, with substantial increases in density of 5-HT innervation occurring during the first two postnatal weeks (Dinopoulos et al., 1997). 5-HT innervation density in the developing hippocampus versus amygdala and the precise timing of when 5-HTergic fibers reach these areas would likely dictate how they are affected by perinatal paroxetine exposure. Furthermore, there are approximately 145 -HT receptor subtypes in the mammalian brain that serve various functions via myriad signaling pathways (Lesch and Waider, 2012). The diversity of 5-HT receptor subtypes and distinct receptor expression patterns in the developing hippocampus versus amygdala could also contribute to the divergent effects of perinatal paroxetine exposure on the transcriptome in these two regions. Future studies should identify why these regions respond differently to perinatal paroxetine (and perhaps other SSRIs), and determine how these unique regional responses contribute to the behavioral consequences of early-life drug exposure. 


\subsection{Unique molecular pathways that are perturbed following perinatal paroxetine exposure}

Bioinformatics analyses of our microarray data identified multiple novel biological processes and molecular pathways that were perturbed in the developing and adult bLR brain following early-life paroxetine exposure. For example, partitional clustering identified functionally-related genes that were regulated by perinatal paroxetine exposure from early postnatal life through adulthood. In the amygdala, two of six gene clusters were enriched with transcripts associated with the hemoglobin complex and intracellular organelles. In the hippocampus, partitional clustering revealed five of ten clusters with gene ontology enrichment; several of these are discussed below.

Transcripts related to synaptic vesicle structure (cluster 4, Fig. 7) were down-regulated in the perinatal paroxetine-exposed hippocampus during the first two postnatal weeks, but upregulated in the adult brain (P75). Hippocampal synaptic markers have been shown to be dysregulated in rodent models relevant to depression, including the Flinder's Sensitive Line (FSL) (Overstreet, 1986, Overstreet et al., 1986a, Overstreet et al., 1986b) and rats exposed to chronic mild stress (Yang et al., 2011, Hu et al., 2013), which is known to enhance rodent anxiety- and depression-like behavior (Willner, 2005). Treating adult FSL rats with the SSRI escitalopram normalized synaptic protein expression and reduced their FST immobility (Musazzi et al., 2010), although SSRI treatment elicits disparate effects depending a subject's age, since paroxetine differentially affected synaptic protein levels when administered to adolescent versus adult animals (Karanges et al., 2013). Overall, these findings suggest that dysregulating synaptic vesicle transport/release contributes to a depressive-like phenotype and that adult SSRI treatment can normalize expression of synaptic proteins. Our observed perinatal paroxetine-induced synaptic marker changes in the developing and adult bLR hippocampus may represent a mechanism related to their exaggerated FST immobility following early-life paroxetine exposure.

Our partitional clustering analysis revealed an enrichment of cytochrome c oxidase (complex IV) subunit transcripts in hippocampal gene cluster 3, indicating that perinatal paroxetine exposure may lead to metabolic dysfunction in the developing and adult hippocampus. Mitochondria can sequester antidepressant drugs, with up to $40 \%$ of fluoxetine levels in the brain concentrated within mitochondria and synaptosomes (Caccia et al., 1990). A variety of antidepressants modulate respiratory chain complex activity, and complex IV appears to be especially susceptible to drugs that increase synaptic 5-HT (Hroudova and Fisar, 2010). Sertraline, one of the most commonly prescribed SSRIs in pregnant women (Wichman et al., 2009, Alwan et al., 2011, Jimenez-Solem et al., 2013), inhibits several complexes in oxidative phosphorylation within isolated mitochondria, and causes cellular ATP depletion in primary rat hepatocytes (Li et al., 2012). In the brain, fluoxetine impairs ATP synthesis, but its effects are probably not occurring through direct interaction with the electron transport chain enzymes. Perinatal SSRI-induced mitochondrial dysfunction in the early postnatal hippocampus when substantial energy is required for cellular remodeling, synaptogenesis and neurogenesis, may represent an important factor that could derail normal hippocampal circuit formation, its downstream function, and its ultimate contribution to regulating emotional behavior (Chen et al., 2013). 
We found that neurogenesis-related transcripts were initially down-regulated in the P7 and P14 hippocampus of perinatal paroxetine-exposed animals but then up-regulated in adulthood. Several of the neurogenesis cluster genes (e.g., Stmn1, Gap43, Timp2) encode proteins that mediate axonal outgrowth and guidance, potentially indicating that perinatal paroxetine exposure impairs integration of hippocampal neurons into developing circuits. Gap-43-null mice exhibit reduced 5-HTergic fiber innervation in the cortex and hippocampus, but, interestingly, show no 5-HT innervation differences in the amygdala (Donovan et al., 2002). Reduced Gap-43 levels in the developing paroxetine-exposed hippocampus may be related to drug-induced reductions of 5-HTergic innervation (Maciag et al., 2006a, Weaver et al., 2010) and offer an explanation for the distinct impact of perinatal paroxetine exposure on the hippocampal versus amygdalar transcriptome.

A previous in vitro study showed that paroxetine treatment increased neurogenesis within hippocampal-derived neural stem cells (Peng et al., 2013), and multiple rodent studies show that multiple classes of antidepressants increase hippocampal neurogenesis in adult animals, which may contribute to antidepressant behavioral effects (Malberg et al., 2000, Malberg and Duman, 2003, Santarelli et al., 2003, Marcussen et al., 2008). Timing may be of the essence, though. While antidepressant-induced neurogenesis changes may be beneficial in the adult brain, such alterations in the developing brain may have negative consequences on neural and emotional development (perhaps eliciting pro-depressant effects rather than antidepressant effects). Overall, the observed differences in neurogenesis-related genes together with perinatal paroxetine-induced changes in genes related to synaptic structure/function and metabolism, suggest a complicated pattern of molecular changes that may reflect druginduced alterations in hippocampal circuit formation. The rodent hippocampus undergoes vast growth and maturation during the early postnatal weeks (Insausti et al., 2010), so paroxetine-induced modification of synaptic remodeling during the critical first three postnatal weeks could permanently impact neural circuit structure and function. Our microarray data suggest that perinatal paroxetine exposure interferes with such hippocampal synaptic remodeling processes, which may alter hippocampal structure, functional connectivity, and ultimately behavior, although future experiments will be required to explore these possibilities.

\subsection{Impact of paroxetine treatment on maternal care in bHR/bLR dams}

The quality and quantity of maternal care critically shapes rodent neurodevelopment, emotional behavior, and hormonal stress responsivity (Francis et al., 1999, Caldji et al., 2000, Meaney, 2001). There are limited reports on the effects of SSRI treatment on rodent maternal behavior. One study reported increased arched-back nursing in dams that were treated with fluoxetine (Pawluski et al., 2012), although another study found no impact of escitalopram on dams' behavior (Bourke et al., 2013a). The present study examined possible paroxetine-induced changes in bHR/bLR maternal behavior to determine a possible mechanism that could explain why bLR offspring are particularly susceptible to the effects of early-life paroxetine exposure while bHR offspring were resistant. We found little impact of paroxetine on maternal behavior in either strain, with no effect of drug treatment on licking/grooming behavior or arched-back nursing. The only observed drug-induced change was that paroxetine-treated bLR mothers engaged in less passive nursing compared to 
vehicle-treated mothers (or either bHR group). The paroxetine-exposed bLR pups appeared to have adequate nutrition since they showed similar pattern of weight gain compared to other groups. The other behavioral difference that we found in paroxetine-exposed dams was that both bHR and bLR drug-treated mothers showed more resting behavior than vehicletreated dams. In summary, although the effects of paroxetine treatment on maternal behavior are minimal, a future cross fostering study could be employed to determine if paroxetineinduced reduction of passive nursing played any role in contributing to bLR offspring's later emotional abnormalities.

\subsection{Technical considerations}

Numerous rodent studies report behavioral and neural abnormalities following perinatal antidepressant exposure. While many findings are consistent across studies, there are discrepancies that likely stem from technical variations, including using different ( $a$ ) antidepressant drugs [chlorimpramine, fluoxetine, citalopram, paroxetine, desipramine, zimeldine, LU-10-134C, nomifensine]; (b) route of drug administration [oral, intraperitoneal injection, osmotic minipump]; (c) species (mouse/rat) or strain used; and (d) timing of drug administration - during pregnancy (Vorhees et al., 1994, Bairy et al., 2007, Forcelli and Heinrichs, 2008, Van den Hove et al., 2008); portions of the first three postnatal weeks (Mirmiran et al., 1981, Hilakivi and Hilakivi, 1987, Hilakivi et al., 1987a, Hilakivi et al., 1987b, Hilakivi et al., 1988, Feenstra et al., 1996, Hansen et al., 1997, Kinney et al., 1997, Vijayakumar and Meti, 1999, Yannielli et al., 1999, Ansorge et al., 2004, Maciag et al., 2006a, Maciag et al., 2006b, Popa et al., 2008, Lee, 2009, Weaver et al., 2010, Simpson et al., 2011); or throughout gestation and the first three postnatal weeks (Lisboa et al., 2007, Bourke et al., 2013b). The vast majority of these studies focus on the effects of neonatal antidepressant exposure on male offspring with the exception of perhaps only one or two studies that also examine effects in females (Lisboa et al., 2007, McAllister et al., 2012). This is an important oversight and a limitation of our own study since our behavioral and gene expression studies used only male offspring. Considering the disproportionate incidence of depression and other mood disorders in women versus men, it is certainly important to consider how females may be differentially impacted by early life antidepressant exposure. Thus, it will be important to include females in future studies to determine if perinatal SSRI exposure elicits similar behavioral and neural effects in bLR females, and whether bHR female offspring are resistant to its effects akin to their male counterparts.

One of the more popular paradigms is injecting pups with antidepressant drugs from P8-21 (Maciag et al., 2006a, Maciag et al., 2006b, Ansorge et al., 2008, Popa et al., 2008, Weaver et al., 2010, Simpson et al., 2011). Ansorge and colleagues conducted an elegant experiment where they analyzed drug levels $1,2,4,8$, and 18 days after drug treatment initiation (collecting blood and brain samples 24 hours after the last injection). Fluoxetine and its metabolite norfluoxetine reached steady state levels after 2-4 days of treatment. Interestingly, they found that clomipramine, citalopram and desipramine did not produce steady state levels, indicating that the injections only lead to transient periods of SERT blockade each day (Ansorge et al., 2008). This highlights one of several important factors that distinguish different types of SSRIs. For instance, SSRIs differ in selectivity for 
serotonin over norepinephrine reuptake transporters (e.g., citalopram is 60 times more selective than fluoxetine and about 12 times more selective than paroxetine(Hyttel, 1993)). Different SSRIs also exhibit varying affinity for non-serotonergic receptors; and have distinct half-lives (e.g., paroxetine half-life in humans is 24 hours (Preskorn, 1993) at a dose of $20 \mathrm{mg} /$ day, but may be longer at higher doses due to autoinhibition; fluoxetine half-life is 2-4 days (Goodnick, 1991, Preskorn, 1993) while its active metabolite, norfluoxetine, has a half-life of 7-15 days; citalopram half-life is 1.5 days(Milne and Goa, 1991)).

For our study, we chose to treat the pregnant and lactating dams with the SSRI paroxetine $(10 \mathrm{mg} / \mathrm{kg} / \mathrm{day})$ via drinking water. This route of administration was chosen, in part, to minimize stress on mothers and pups, since previous studies show that both bHRs and bLRs are particularly stress-sensitive (Kabbaj et al., 2000, Kabbaj, 2004, Clinton et al., 2008, Stedenfeld et al., 2011). This drug-treatment method was previously shown to reduce depression-like behavior in adult rodents (Muigg et al., 2007), which is consistent with our results in Experiment 1 showing that chronic paroxetine given in drinking water reduced adult bLR males' FST immobility. One caveat to this method of administration is that as the pups become more mobile during the second or third postnatal weeks, they are likely receiving paroxetine directly via drinking water, likely inflating the dose they are receiving.

Our treatment paradigm lead to paroxetine serum levels of $147 \mathrm{ng} / \mathrm{ml}$ and brain tissue levels of $1.94 \mu \mathrm{g} / \mathrm{g}$ in adult animals (values averaged across bHR/bLR animals since there were no phenotypic differences). We found a clear effect of perinatal paroxetine exposure on bLRs' adult behavior (paradoxically increasing FST immobility) while bHR offspring were not affected, although a limitation of our study is that we only confirmed paroxetine levels in brain tissue from drug-exposed bLR pups and unfortunately did not have bHR brain tissue samples available for similar analysis. The concentration of paroxetine in brain tissue of $\mathrm{P} 7$ pups was notably lower $(0.28 \mu \mathrm{g} / \mathrm{g})$ than drug levels observed in brain tissue of adult drugtreated bHR/bLR animals $(1.94 \mu \mathrm{g} / \mathrm{g})$. This is expected, though, as only a fraction of the maternal dose is transferred via lactation. We found that serum paroxetine levels in chronically-treated adult bHR/bLR rats were analogous to the plasma levels previously reported in adult paroxetine-treated rats (Muigg et al., 2007, Karanges et al., 2011) and within the human therapeutic range (DeVane, 1999). Prior studies indicate that placental transfer of drug to offspring range from $30-70 \%$ of the maternal dose for fluvoxamine and fluoxetine (Noorlander et al., 2008). Besides sertraline, paroxetine reportedly has the lowest placental transfer ratio in humans despite its elevated teratogenic risks relative to other SSRIs (Hendrick et al., 2003). In future experiments, determining the paroxetine concentration in utero (or perhaps at birth) will be of utmost interest to determine the amount of drug the offspring are exposed to throughout gestation and whether placental transfer of paroxetine differs in bHRs versus bLRs.

Finally, one drawback of our microarray experiment is that we solely focused on perinatal paroxetine-induced gene expression changes in developing and adult bLR offspring, without also examining such effects in bHRs. It was cost prohibitive to include these additional experimental groups, although it would have provided useful information in terms of whether neonatal paroxetine exposure specifically perturbs bLRs' developmental gene 
expression (as it selectively elicits behavioral abnormalities), while bHRs may have not been affected.

Conclusions-Human and rodent studies alike point to potential hazards of early-life SSRI exposure. Our present data concur with previous work showing that neonatal exposure to SSRI paroxetine elicits lasting emotional behavior abnormalities. An important contribution of the present work is that we demonstrate individual differences in vulnerability to these effects, showing that rats predisposed to an anxiety-/depression-like phenotype (bLR) were particularly susceptible to the behavioral consequences of perinatal paroxetine exposure, while animals that typically exhibit low spontaneous levels of anxiety-/ depression-like behavior coupled with high risk-taking/aggression/impulsivity (bHR) are resistant to its effects. Moreover, our microarray experiment revealed widespread perinatal paroxetine-induced gene expression changes in the developing and adult brain, particularly the hippocampus. Our results unveiled novel molecular pathways that are perturbed in response to neonatal paroxetine exposure, pointing to potential neurobiological mechanisms that underlie its effects on emotional behavior. Of course, it is important to keep in mind the significant differences in the drug metabolism, placental drug transfer, and neurodevelopmental timelines between rodents and humans when attempting to extrapolate rodent findings to humans (as well as possible differences that exist between different classes of antidepressants or different types of SSRIs). Nonetheless, rodent models such as ours offer indispensable tools to better understand neurobiological mechanisms relevant to perinatal SSRI exposure, and may be helpful in identifying treatment alternatives that will maximize health and safety of depressed mothers and their children.

\section{Acknowledgments}

We are very grateful to Antony Abraham, Tracy Bedrosian, Hailey Orr, and Kate Mills for excellent technical assistance. The study was funded by NIMH 4R00MH085859-02 (SMC), Office of Naval Research ONRN00014-09-1-0598 (HA), and NIDA PPG 5P01DA021633-02 (HA).

\section{Abbreviations}

$\begin{array}{ll}\text { SSRI } & \text { Selective Serotonin Reuptake Inhibitor } \\ \text { bLR } & \text { bred-Low Responder } \\ \text { bHR } & \text { bred-High Responder } \\ \text { 5-HT } & \text { Serotonin } \\ \text { TPH2 } & \text { Tryptophan Hydroxylase 2 } \\ \text { SERT } & \text { Serotonin Transporter } \\ \text { FST } & \text { Forced Swim Test } \\ \text { OFT } & \text { Open Field Test } \\ \text { EPM } & \text { Elevated Plus Maze } \\ \text { GO } & \text { Gene Ontology }\end{array}$


FWER Family-wise Error Rate

\section{References}

Alwan S, Friedman JM. Safety of selective serotonin reuptake inhibitors in pregnancy. CNS Drugs. 2009; 23:493-509. [PubMed: 19480468]

Alwan S, Reefhuis J, Rasmussen SA, Friedman JM. Patterns of antidepressant medication use among pregnant women in a United States population. J Clin Pharmacol. 2011; 51:264-270. [PubMed: 20663997]

Alwan S, Reefhuis J, Rasmussen SA, Olney RS, Friedman JM. Use of selective serotonin-reuptake inhibitors in pregnancy and the risk of birth defects. N Engl J Med. 2007; 356:2684-2692. [PubMed: 17596602]

Andersen SL, Greene-Colozzi EA, Sonntag KC. A novel, multiple symptom model of obsessivecompulsive-like behaviors in animals. Biological psychiatry. 2010; 68:741-747. [PubMed: 20619828]

Ansorge M, Morelli E, Gingrich J. Inhibition of serotonin but not norepinephrine transport during development produces delayed, persistent perturbations of emotional behaviors in mice. J Neurosci. 2008; 28:199-207. [PubMed: 18171937]

Ansorge MS, Zhou M, Lira A, Hen R, Gingrich JA. Early-life blockade of the 5-HT transporter alters emotional behavior in adult mice. Science. 2004; 306:879-881. [PubMed: 15514160]

Bairy KL, Madhyastha S, Ashok KP, Bairy I, Malini S. Developmental and behavioral consequences of prenatal fluoxetine. Pharmacology. 2007; 79:1-11. [PubMed: 17077648]

Bakker MK, Kerstjens-Frederikse WS, Buys CH, de Walle HE, de Jong-van den Berg LT. Firsttrimester use of paroxetine and congenital heart defects: a population-based case-control study. Birth Defects Res A Clin Mol Teratol. 2010; 88:94-100. [PubMed: 19937603]

Ballaz SJ, Akil H, Watson SJ. The 5-HT7 receptor: role in novel object discrimination and relation to novelty-seeking behavior. Neuroscience. 2007a; 149:192-202. [PubMed: 17869441]

Ballaz SJ, Akil H, Watson SJ. Analysis of 5-HT6 and 5-HT7 receptor gene expression in rats showing differences in novelty-seeking behavior. Neuroscience. 2007b; 147:428-438. [PubMed: 17543469]

Bar-Oz B, Einarson T, Einarson A, Boskovic R, O’Brien L, Malm H, Berard A, Koren G. Paroxetine and congenital malformations: meta-Analysis and consideration of potential confounding factors. Clin Ther. 2007; 29:918-926. [PubMed: 17697910]

Bennett HA, Einarson A, Taddio A, Koren G, Einarson TR. Prevalence of depression during pregnancy: systematic review. Obstet Gynecol. 2004; 103:698-709. [PubMed: 15051562]

Berard A, Ramos E, Rey E, Blais L, St-Andre M, Oraichi D. First trimester exposure to paroxetine and risk of cardiac malformations in infants: the importance of dosage. Birth Defects Res B Dev Reprod Toxicol. 2007; 80:18-27. [PubMed: 17187388]

Blanchard MM, Mendelsohn D, Stamp JA. The HR/LR model: Further evidence as an animal model of sensation seeking. Neurosci Biobehav Rev. 2009; 33:1145-1154. [PubMed: 19497336]

Borri C, Mauri M, Oppo A, Banti S, Rambelli C, Ramacciotti D, Montagnani MS, Camilleri V, Cortopassi S, Bettini A, Ricciardulli S, Rucci P, Montaresi S, Cassano GB. Axis I psychopathology and functional impairment at the third month of pregnancy: Results from the Perinatal Depression-Research and Screening Unit (PND-ReScU) study. J Clin Psychiatry. 2008; 69:1617-1624. [PubMed: 19192445]

Bosch OJ. Maternal nurturing is dependent on her innate anxiety: the behavioral roles of brain oxytocin and vasopressin. Horm Behav. 2011; 59:202-212. [PubMed: 21094649]

Bourke CH, Capello CF, Rogers SM, Yu ML, Boss-Williams KA, Weiss JM, Stowe ZN, Owens MJ. Prenatal exposure to escitalopram and/or stress in rats: a prenatal stress model of maternal depression and its treatment. Psychopharmacology (Berl). 2013a; 228:231-241. [PubMed: 23436130] 
Bourke CH, Stowe ZN, Neigh GN, Olson DE, Owens MJ. Prenatal exposure to escitalopram and/or stress in rats produces limited effects on endocrine, behavioral, or gene expression measures in adult male rats. Neurotoxicology and teratology. 2013b; 39:100-109. [PubMed: 23906943]

Caccia S, Cappi M, Fracasso C, Garattini S. Influence of dose and route of administration on the kinetics of fluoxetine and its metabolite norfluoxetine in the rat. Psychopharmacology (Berl). 1990; 100:509-514. [PubMed: 2320712]

Caldji C, Diorio J, Meaney MJ. Variations in maternal care in infancy regulate the development of stress reactivity. Biological psychiatry. 2000; 48:1164-1174. [PubMed: 11137058]

Calvo N, Cecchi M, Kabbaj M, Watson SJ, Akil H. Differential effects of social defeat in rats with high and low locomotor response to novelty. Neuroscience. 2011; 183:81-89. [PubMed: 21453756]

Capriles N, Watson S Jr, Akil H. Individual differences in the improvement of cocaine-induced place preference response by the 5-HT2C receptor antagonist SB242084 in rats. Psychopharmacology (Berl). 2012; 220:731-740. [PubMed: 21989806]

Carlson JN, Visker KE, Nielsen DM, Keller RW Jr, Glick SD. Chronic antidepressant drug treatment reduces turning behavior and increases dopamine levels in the medial prefrontal cortex. Brain Res. 1996; 707:122-126. [PubMed: 8866721]

Casper RC, Fleisher BE, Lee-Ancajas JC, Gilles A, Gaylor E, DeBattista A, Hoyme HE. Follow-up of children of depressed mothers exposed or not exposed to antidepressant drugs during pregnancy. $\mathrm{J}$ Pediatr. 2003; 142:402-408. [PubMed: 12712058]

Chen F, Wegener G, Madsen TM, Nyengaard JR. Mitochondrial plasticity of the hippocampus in a genetic rat model of depression after antidepressant treatment. Synapse. 2013; 67:127-134. [PubMed: 23152197]

Clements CC, Castro VM, Blumenthal SR, Rosenfield HR, Murphy SN, Fava M, Erb JL, Churchill SE, Kaimal AJ, Doyle AE, Robinson EB, Smoller JW, Kohane IS, Perlis RH. Prenatal antidepressant exposure is associated with risk for attention-deficit hyperactivity disorder but not autism spectrum disorder in a large health system. Mol Psychiatry. 2014

Clinton SM, Bedrosian TA, Abraham AD, Watson SJ, Akil H. Neural and environmental factors impacting maternal behavior differences in high- versus low-novelty-seeking rats. Horm Behav. 2010; 57:463-473. [PubMed: 20156440]

Clinton SM, Kerman IA, Orr HR, Bedrosian TA, Abraham AD, Simpson DN, Watson SJ, Akil H. Pattern of forebrain activation in high novelty-seeking rats following aggressive encounter. Brain Res. 2011a; 1422:20-31. [PubMed: 21974861]

Clinton SM, Miller S, Watson SJ, Akil H. Prenatal stress does not alter innate novelty-seeking behavioral traits, but differentially affects individual differences in neuroendocrine stress responsivity. Psychoneuroendocrinology. 2008; 33:162-177. [PubMed: 18077099]

Clinton SM, Stead JD, Miller S, Watson SJ, Akil H. Developmental underpinnings of differences in rodent novelty-seeking and emotional reactivity. Eur J Neurosci. 2011b; 34:994-1005. [PubMed: 21864320]

Clinton SM, Watson SJ, Akil H. High novelty-seeking rats are resilient to negative physiological effects of the early life stress. Stress. 2014; 17:97-107. [PubMed: 24090131]

Cole JA, Ephross SA, Cosmatos IS, Walker AM. Paroxetine in the first trimester and the prevalence of congenital malformations. Pharmacoepidemiol Drug Saf. 2007; 16:1075-1085. [PubMed: 17729379]

Cordes SP. Molecular genetics of the early development of hindbrain serotonergic neurons. Clin Genet. 2005; 68:487-494. [PubMed: 16283875]

Croen LA, Grether Judith K, Yoshida Cathleen K, Odouli Roxana, Hendrick Victoria. Antidepressant use during pregnancy and childhood autism spectrum disorders. Arch Gen Psychiatry. 2011; 68:1104-1112. [PubMed: 21727247]

Cryan JF, Valentino RJ, Lucki I. Assessing substrates underlying the behavioral effects of antidepressants using the modified rat forced swimming test. Neurosci Biobehav Rev. 2005; 29:547-569. [PubMed: 15893822] 
Cummings JA, Clinton SM, Perry AN, Akil H, Becker JB. Male rats that differ in novelty exploration demonstrate distinct patterns of sexual behavior. Behavioral neuroscience. 2013; 127:47-58. [PubMed: 23398441]

Darling RD, Alzghoul L, Zhang J, Khatri N, Paul IA, Simpson KL, Lin RC. Perinatal citalopram exposure selectively increases locus ceruleus circuit function in male rats. J Neurosci. 2011; 31:16709-16715. [PubMed: 22090498]

Dayan J, Creveuil C, Herlicoviez M, Herbel C, Baranger E, Savoye C, Thouin A. Role of anxiety and depression in the onset of spontaneous preterm labor. Am J Epidemiol. 2002; 155:293-301. [PubMed: 11836191]

DeVane CL. Metabolism and pharmacokinetics of selective serotonin reuptake inhibitors. Cell Mol Neurobiol. 1999; 19:443-466. [PubMed: 10379420]

Diav-Citrin O, Shechtman S, Weinbaum D, Wajnberg R, Avgil M, Di Gianantonio E, Clementi M, Weber-Schoendorfer C, Schaefer C, Ornoy A. Paroxetine and fluoxetine in pregnancy: a prospective, multicentre, controlled, observational study. Br J Clin Pharmacol. 2008; 66:695-705. [PubMed: 18754846]

Dinopoulos A, Dori I, Parnavelas JG. The serotonin innervation of the basal forebrain shows a transient phase during development. Brain Res Dev Brain Res. 1997; 99:38-52.

Donovan SL, Mamounas LA, Andrews AM, Blue ME, McCasland JS. GAP-43 is critical for normal development of the serotonergic innervation in forebrain. J Neurosci. 2002; 22:3543-3552. [PubMed: 11978831]

Eilam D, Golani I. The ontogeny of exploratory behavior in the house rat (Rattus rattus): the mobility gradient. Developmental Psychobiology. 1988; 21:679-710. [PubMed: 3234601]

Einarson A, Pistelli A, DeSantis M, Malm H, Paulus WD, Panchaud A, Kennedy D, Einarson TR, Koren G. Evaluation of the risk of congenital cardiovascular defects associated with use of paroxetine during pregnancy. Am J Psychiatry. 2008; 165:749-752. [PubMed: 18381907]

Everett JW, Sawyer CH. A neural timing factor in the mechanism by which progesterone advances ovulation in the cyclic rat. Endocrinology. 1949; 45:581-595. illust. [PubMed: 15409386]

Feenstra MG, van Galen H, Te Riele PJ, Botterblom MH, Mirmiran M. Decreased hypothalamic serotonin levels in adult rats treated neonatally with clomipramine. Pharmacol Biochem Behav. 1996; 55:647-652. [PubMed: 8981596]

Flagel SB, Waselus M, Clinton SM, Watson SJ, Akil H. Antecedents and consequences of drug abuse in rats selectively bred for high and low response to novelty. Neuropharmacology. 2014; 76(Pt B): 425-436. [PubMed: 23639434]

Forcelli PA, Heinrichs SC. Teratogenic effects of maternal antidepressant exposure on neural substrates of drug-seeking behavior in offspring. Addict Biol. 2008; 13:52-62. [PubMed: 17850417]

Francis DD, Champagne FA, Liu D, Meaney MJ. Maternal care, gene expression, and the development of individual differences in stress reactivity. Annals of the New York Academy of Science. 1999; 896:66-84.

Frankova S, Mikulecka A. Ontogeny of social behavior of pups of laboratory rats genetically selected for activity level. Activitas Nervosa Superior (Praha). 1990; 32:167-173.

Garcia-Fuster MJ, Parks GS, Clinton SM, Watson SJ, Akil H, Civelli O. The melanin-concentrating hormone $(\mathrm{MCH})$ system in an animal model of depression-like behavior. Eur Neuropsychopharmacol. 2011

Gaspar P, Cases O, Maroteaux L. The developmental role of serotonin: news from mouse molecular genetics. Nat Rev Neurosci. 2003; 4:1002-1012. [PubMed: 14618156]

Gentile S, Galbally M. Prenatal exposure to antidepressant medications and neurodevelopmental outcomes: a systematic review. J Affect Disord. 2011; 128:1-9. [PubMed: 20303599]

Goodnick PJ. Pharmacokinetics of second generation antidepressants: fluoxetine. Psychopharmacol Bull. 1991; 27:503-512. [PubMed: 1813897]

Grigoriadis S, VonderPorten EH, Mamisashvili L, Roerecke M, Rehm J, Dennis CL, Koren G, Steiner M, Mousmanis P, Cheung A, Ross LE. Antidepressant exposure during pregnancy and congenital malformations: is there an association? A systematic review and meta-analysis of the best evidence. J Clin Psychiatry. 2013; 74:e293-308. [PubMed: 23656855] 
Hansen HH, Sanchez C, Meier E. Neonatal administration of the selective serotonin reuptake inhibitor Lu 10-134-C increases forced swimming-induced immobility in adult rats: a putative animal model of depression? J Pharmacol Exp Ther. 1997; 283:1333-1341. [PubMed: 9400008]

Harrington RA, Lee LC, Crum RM, Zimmerman AW, Hertz-Picciotto I. Serotonin hypothesis of autism: implications for selective serotonin reuptake inhibitor use during pregnancy. Autism Res. 2013; 6:149-168. [PubMed: 23495208]

Harris SS, Maciag D, Simpson KL, Lin RC, Paul IA. Dose-dependent effects of neonatal SSRI exposure on adult behavior in the rat. Brain Res. 2012; 1429:52-60. [PubMed: 22079319]

Hartley PS, John Sheward W, French K, Horn JM, Holmes MC, Harmar AJ. Food-entrained rhythmic expression of PER2 and BMAL1 in murine megakaryocytes does not correlate with circadian rhythms in megakaryopoiesis. J Thromb Haemost. 2008; 6:1144-1152. [PubMed: 18419744]

Hayes RM, Wu P, Shelton RC, Cooper WO, Dupont WD, Mitchel E, Hartert TV. Maternal antidepressant use and adverse outcomes: a cohort study of 228,876 pregnancies. Am J Obstet Gynecol. 2012; 207:49, e41-49. [PubMed: 22727349]

Heim CPPM, Nemeroff CB. Importance of studying the contributions of early adverse experience to neurobiological findings in depression. Neuropsychopharmacology. 2004; 29:641-648. [PubMed: 15034558]

Hendrick V, Stowe ZN, Altshuler LL, Hwang S, Lee E, Haynes D. Placental passage of antidepressant medications. Am J Psychiatry. 2003; 160:993-996. [PubMed: 12727706]

Hilakivi LA, Hilakivi I. Increased adult behavioral 'despair' in rats neonatally exposed to desipramine or zimeldine: an animal model of depression? Pharmacol Biochem Behav. 1987; 28:367-369. [PubMed: 2960986]

Hilakivi LA, Hilakivi I, Ahtee L, Haikala H, Attila M. Effect of neonatal nomifensine exposure on adult behavior and brain monoamines in rats. J Neural Transm. 1987a; 70:99-116. [PubMed: 3668522]

Hilakivi LA, Hilakivi I, Kiianmaa K. Neonatal antidepressant administration suppresses concurrent active (REM) sleep and increases adult alcohol consumption in rats. Alcohol Alcohol Suppl. 1987b; 1:339-343. [PubMed: 2447903]

Hilakivi LA, Taira T, Hilakivi I, Loikas P. Neonatal treatment with monoamine uptake inhibitors alters later response in behavioural 'despair' test to beta and GABA-B receptor agonists. Pharmacol Toxicol. 1988; 63:57-61. [PubMed: 2969507]

Homberg JR, Schubert D, Gaspar P. New perspectives on the neurodevelopmental effects of SSRIs. Trends Pharmacol Sci. 2010; 31:60-65. [PubMed: 19963284]

Hroudova J, Fisar Z. Activities of respiratory chain complexes and citrate synthase influenced by pharmacologically different antidepressants and mood stabilizers. Neuro Endocrinol Lett. 2010; 31:336-342. [PubMed: 20588251]

Hu Y, Zhou J, Fang L, Liu H, Zhan Q, Luo D, Zhou C, Chen J, Li Q, Xie P. Hippocampal synaptic dysregulation of exo/endocytosis-associated proteins induced in a chronic mild-stressed rat model. Neuroscience. 2013; 230:1-12. [PubMed: 22922266]

Hyttel J. Comparative pharmacology of selective serotonin reuptake inhibitors (SSRIs). Nord J Psychiatry. 1993; 47 (suppl 30):5-12.

Insausti R, Cebada-Sanchez S, Marcos P. Postnatal development of the human hippocampal formation. Adv Anat Embryol Cell Biol. 2010; 206:1-86. [PubMed: 20329667]

Jama A, Cecchi M, Calvo N, Watson SJ, Akil H. Inter-individual differences in novelty-seeking behavior in rats predict differential responses to desipramine in the forced swim test. Psychopharmacology. 2008

Jimenez-Solem E, Andersen JT, Petersen M, Broedbaek K, Andersen NL, Torp-Pedersen C, Poulsen HE. Prevalence of antidepressant use during pregnancy in Denmark, a nation-wide cohort study. PLoS One. 2013; 8:e63034. [PubMed: 23638179]

Jimenez-Solem E, Andersen JT, Petersen M, Broedbaek K, Jensen JK, Afzal S, Gislason GH, TorpPedersen C, Poulsen HE. Exposure to selective serotonin reuptake inhibitors and the risk of congenital malformations: a nationwide cohort study. BMJ Open. 2012:2. 
Kabbaj M. Neurobiological bases of individual differences in emotional and stress responsiveness: high responders-low responders model. Archives of Neurology. 2004; 61:1009-1012. [PubMed: 15262729]

Kabbaj M, Devine DP, Savage VR, Akil H. Neurobiological correlates of individual differences in novelty-seeking behavior in the rat: differential expression of stress-related molecules. Journal of Neuroscience. 2000; 20:6983-6988. [PubMed: 10995843]

Kallen B, Otterblad Olausson P. Antidepressant drugs during pregnancy and infant congenital heart defect. Reprod Toxicol. 2006; 21:221-222. [PubMed: 16406480]

Karanges E, Li KM, Motbey C, Callaghan PD, Katsifis A, McGregor IS. Differential behavioural and neurochemical outcomes from chronic paroxetine treatment in adolescent and adult rats: a model of adverse antidepressant effects in human adolescents? Int J Neuropsychopharmacol. 2011; 14:491-504. [PubMed: 21329552]

Karanges EA, Kashem MA, Sarker R, Ahmed EU, Ahmed S, Van Nieuwenhuijzen PS, Kemp AH, McGregor IS. Hippocampal protein expression is differentially affected by chronic paroxetine treatment in adolescent and adult rats: a possible mechanism of "paradoxical" antidepressant responses in young persons. Front Pharmacol. 2013; 4:86. [PubMed: 23847536]

Kerman IA, Clinton SM, Bedrosian TA, Abraham AD, Rosenthal DT, Akil H, Watson SJ. High novelty-seeking predicts aggression and gene expression differences within defined serotonergic cell groups. Brain Res. 2011

Kessler RC, Berglund P, Demler O, Jin R, Koretz D, Merikangas KR, Rush AJ, Walters EE, Wang PS. The epidemiology of major depressive disorder: results from the National Comorbidity Survey Replication (NCS-R). JAMA: the journal of the American Medical Association. 2003; 289:30953105.

Kessler RCBP, Demler O, Jin R, Merikangas KR, Walters EE. Lifetime Prevalence and Age-of-Onset Distributions of DSM-IV Disorders in the National Comorbidity Survey Replication. Arch Gen Psychiatry. 2005; 62:593-602. [PubMed: 15939837]

Kinney GG, Vogel GW, Feng P. Decreased dorsal raphe nucleus neuronal activity in adult chloral hydrate anesthetized rats following neonatal clomipramine treatment: implications for endogenous depression. Brain Res. 1997; 756:68-75. [PubMed: 9187315]

Klinger G, Frankenthal D, Merlob P, Diamond G, Sirota L, Levinson-Castiel R, Linder N, Stahl B, Inbar D. Long-term outcome following selective serotonin reuptake inhibitor induced neonatal abstinence syndrome. J Perinatol. 2011; 31:615-620. [PubMed: 21311497]

Kornum JB, Nielsen RB, Pedersen L, Mortensen PB, Norgaard M. Use of selective serotonin-reuptake inhibitors during early pregnancy and risk of congenital malformations: updated analysis. Clin Epidemiol. 2010; 2:29-36. [PubMed: 20865100]

Ladd COHRL, Thrivikraman KV, Nemeroff CB, Meaney MJ, Plotsky PM. Long-term behavioral and neuroendocrine adaptations to adverse early experience. Progress in Brain Research. 2000; 122:81-103. [PubMed: 10737052]

Landgraf R, Wigger A. High versus low anxiety-related behavior rats: an animal model of extremes in trait anxiety. Behavioral Genetics. 2002; 32:301-314.

Lee LJ. Neonatal fluoxetine exposure affects the neuronal structure in the somatosensory cortex and somatosensory-related behaviors in adolescent rats. Neurotox Res. 2009; 15:212-223. [PubMed: 19384594]

Lee LJ, Lee LJ. Neonatal fluoxetine exposure alters motor performances of adolescent rats. Dev Neurobiol. 2012; 72:1122-1132. [PubMed: 21714104]

Lesch KP, Waider J. Serotonin in the modulation of neural plasticity and networks: implications for neurodevelopmental disorders. Neuron. 2012; 76:175-191. [PubMed: 23040814]

Li Y, Couch L, Higuchi M, Fang JL, Guo L. Mitochondrial dysfunction induced by sertraline, an antidepressant agent. Toxicol Sci. 2012; 127:582-591. [PubMed: 22387747]

Lisboa S, Oliveira P, Costa L, Venancio E, Moreira E. Behavioral evaluation of male and female mice pups exposed to fluoxetine during pregnancy and lactation. Pharmacology. 2007; 80:49-56. [PubMed: 17519559] 
Louik C, Lin AE, Werler MM, Hernandez-Diaz S, Mitchell AA. First-trimester use of selective serotonin-reuptake inhibitors and the risk of birth defects. N Engl J Med. 2007; 356:2675-2683. [PubMed: 17596601]

Lowry CA, Hale MW, Evans AK, Heerkens J, Staub DR, Gasser PJ, Shekhar A. Serotonergic systems, anxiety, and affective disorder: focus on the dorsomedial part of the dorsal raphe nucleus. Ann N Y Acad Sci. 2008; 1148:86-94. [PubMed: 19120094]

Maciag D, Simpson K, Coppinger D, Lu Y, Wang Y, Lin R, Paul I. Neonatal antidepressant exposure has lasting effects on behavior and serotonin circuitry. Neuropsychopharmacology: official publication of the American College of Neuropsychopharmacology. 2006a; 31:47-57. [PubMed: 16012532]

Maciag D, Williams L, Coppinger D, Paul I. Neonatal citalopram exposure produces lasting changes in behavior which are reversed by adult imipramine treatment. Eur J Pharmacol. 2006b; 532:265269. [PubMed: 16483567]

Malberg JE, Duman RS. Cell proliferation in adult hippocampus is decreased by inescapable stress: reversal by fluoxetine treatment. Neuropsychopharmacology: official publication of the American College of Neuropsychopharmacology. 2003; 28:1562-1571. [PubMed: 12838272]

Malberg JE, Eisch AJ, Nestler EJ, Duman RS. Chronic antidepressant treatment increases neurogenesis in adult rat hippocampus. J Neurosci. 2000; 20:9104-9110. [PubMed: 11124987]

Malm H, Klaukka T, Neuvonen PJ. Risks associated with selective serotonin reuptake inhibitors in pregnancy. Obstet Gynecol. 2005; 106:1289-1296. [PubMed: 16319254]

Marcus SM. Depression during pregnancy: rates, risks and consequences--Motherisk Update 2008. Can J Clin Pharmacol. 2009; 16:e15-22. [PubMed: 19164843]

Marcussen AB, Flagstad P, Kristjansen PE, Johansen FF, Englund U. Increase in neurogenesis and behavioural benefit after chronic fluoxetine treatment in Wistar rats. Acta Neurol Scand. 2008; 117:94-100. [PubMed: 18184344]

Marquez C, Nadal R, Armario A. Influence of reactivity to novelty and anxiety on hypothalamicpituitary-adrenal and prolactin responses to two different novel environments in adult male rats. Behavioural brain research. 2006; 168:13-22. [PubMed: 16303185]

McAllister BB, Kiryanova V, Dyck RH. Behavioural outcomes of perinatal maternal fluoxetine treatment. Neuroscience. 2012; 226:356-366. [PubMed: 23000627]

Meaney MJ. Maternal care, gene expression, and the transmission of individual differences in stress reactivity across generations. Annual Review of Neuroscience. 2001; 24:1161-1192.

Milne RJ, Goa KL. Citalopram. A review of its pharmacodynamic and pharmacokinetic properties, and therapeutic potential in depressive illness. Drugs. 1991; 41:450-477. [PubMed: 1711447]

Mirmiran M, van de Poll NE, Corner MA, van Oyen HG, Bour HL. Suppression of active sleep by chronic treatment with chlorimipramine during early postnatal development: effects upon adult sleep and behavior in the rat. Brain Res. 1981; 204:129-146. [PubMed: 7195762]

Muigg P, Hoelzl U, Palfrader K, Neumann I, Wigger A, Landgraf R, Singewald N. Altered brain activation pattern associated with drug-induced attenuation of enhanced depression-like behavior in rats bred for high anxiety. Biological psychiatry. 2007; 61:782-796. [PubMed: 17224133]

Musazzi L, Mallei A, Tardito D, Gruber SH, El Khoury A, Racagni G, Mathe AA, Popoli M. Earlylife stress and antidepressant treatment involve synaptic signaling and Erk kinases in a geneenvironment model of depression. J Psychiatr Res. 2010; 44:511-520. [PubMed: 20003989]

Noorlander C, Ververs F, Nikkels P, van Echteld C, Visser G, Smidt M. Modulation of serotonin transporter function during fetal development causes dilated heart cardiomyopathy and lifelong behavioral abnormalities. PloS one. 2008:3.

Oberlander T, Gingrich J, Ansorge M. Sustained neurobehavioral effects of exposure to SSRI antidepressants during development: molecular to clinical evidence. Clinical pharmacology and therapeutics. 2009; 86:672-677. [PubMed: 19890255]

Oberlander TF. Fetal Serotonin Signaling: Setting Pathways for Early Childhood Development and Behavior. Journal of Adolescent Health. 2012; 55:S9-S16. [PubMed: 22794534]

Oberlander TF, Bonaguro RJ, Misri S, Papsdorf M, Ross CJ, Simpson EM. Infant serotonin transporter (SLC6A4) promoter genotype is associated with adverse neonatal outcomes after prenatal 
exposure to serotonin reuptake inhibitor medications. Mol Psychiatry. 2008a; 13:65-73. [PubMed: 17519929]

Oberlander TF, Grunau R, Mayes L, Riggs W, Rurak D, Papsdorf M, Misri S, Weinberg J. Hypothalamic-pituitary-adrenal (HPA) axis function in 3-month old infants with prenatal selective serotonin reuptake inhibitor (SSRI) antidepressant exposure. Early Hum Dev. 2008b; 84:689-697. [PubMed: 18639992]

Oberlander TF, Grunau RE, Fitzgerald C, Papsdorf M, Rurak D, Riggs W. Pain reactivity in 2-monthold infants after prenatal and postnatal serotonin reuptake inhibitor medication exposure. Pediatrics. 2005; 115:411-425. [PubMed: 15687451]

Oberlander TF, Papsdorf M, Brain UM, Misri S, Ross C, Grunau RE. Prenatal effects of selective serotonin reuptake inhibitor antidepressants, serotonin transporter promoter genotype (SLC6A4), and maternal mood on child behavior at 3 years of age. Arch Pediatr Adolesc Med. 2010; 164:444-451. [PubMed: 20439795]

Oberlander TF, Warburton W, Misri S, Riggs W, Aghajanian J, Hertzman C. Major congenital malformations following prenatal exposure to serotonin reuptake inhibitors and benzodiazepines using population-based health data. Birth Defects Res B Dev Reprod Toxicol. 2008c; 83:68-76. [PubMed: 18293409]

Olivier JD, Blom T, Arentsen T, Homberg JR. The age-dependent effects of selective serotonin reuptake inhibitors in humans and rodents: A review. Prog Neuropsychopharmacol Biol Psychiatry. 2011; 35:1400-1408. [PubMed: 20883714]

Overstreet DH. Selective breeding for increased cholinergic function: development of a new animal model of depression. Biological psychiatry. 1986; 21:49-58. [PubMed: 3942800]

Overstreet DH, Booth RA, Dana R, Risch SC, Janowsky DS. Enhanced elevation of corticosterone following arecoline administration to rats selectively bred for increased cholinergic function. Psychopharmacology (Berl). 1986a; 88:129-130. [PubMed: 3080772]

Overstreet DH, Janowsky DS, Gillin JC, Shiromani PJ, Sutin EL. Stress-induced immobility in rats with cholinergic supersensitivity. Biological psychiatry. 1986b; 21:657-664. [PubMed: 3708037]

Pawluski JL, Charlier TD, Fillet M, Houbart V, Crispin HT, Steinbusch HW, van den Hove DL. Chronic fluoxetine treatment and maternal adversity differentially alter neurobehavioral outcomes in the rat dam. Behav Brain Res. 2012; 228:159-168. [PubMed: 22173000]

Pedersen LH, Henriksen TB, Vestergaard M, Olsen J, Bech BH. Selective serotonin reuptake inhibitors in pregnancy and congenital malformations: population based cohort study. BMJ. 2009; 339:b3569. [PubMed: 19776103]

Peng ZW, Xue F, Wang HN, Zhang RG, Chen YC, Wang Y, Zhang LY, Fan J, Tan QR. Paroxetine up-regulates neurogenesis in hippocampus-derived neural stem cell from fetal rats. Mol Cell Biochem. 2013; 375:105-113. [PubMed: 23291919]

Piazza PV, Deminiere JM, Le Moal M, Simon H. Factors that predict individual vulnerability to amphetamine self-administration. Science. 1989; 245:1511-1513. [PubMed: 2781295]

Piazza PV, Deroche V, Deminiere JM, Maccari S, Le Moal M, Simon H. Corticosterone in the range of stress-induced levels possesses reinforcing properties: implications for sensation-seeking behaviors. Proceedings of the National Academy of Science of the USA. 1993; 90:11738-11742.

Popa D, Lena C, Alexandre C, Adrien J. Lasting syndrome of depression produced by reduction in serotonin uptake during postnatal development: evidence from sleep, stress, and behavior. J Neurosci. 2008; 28:3546-3554. [PubMed: 18385313]

Porsolt RD, Le Pichon M, Jalfre M. Depression: a new animal model sensitive to antidepressant treatments. Nature. 1977; 266:730-732. [PubMed: 559941]

Preskorn SH. Pharmacokinetics of antidepressants: why and how they are relevant to treatment. J Clin Psychiatry. 1993; 54(Suppl):14-34. discussion 55-16. [PubMed: 8407856]

Rai D, Lee, Brian K, Dalman Christina, Golding Jean, Lewis Glyn, Magnusson Cecilia. Parental depression, maternal antidepressant use during pregnancy, and risk of autism spectrum disorders: population based case-control study. British Medical Journal. 2013:346.

Ross LE, Grigoriadis S, Mamisashvili L, Vonderporten EH, Roerecke M, Rehm J, Dennis CL, Koren G, Steiner M, Mousmanis P, Cheung A. Selected pregnancy and delivery outcomes after 
exposure to antidepressant medication: a systematic review and meta-analysis. JAMA psychiatry. 2013; 70:436-443. [PubMed: 23446732]

Santarelli L, Saxe M, Gross C, Surget A, Battaglia F, Dulawa S, Weisstaub N, Lee J, Duman R, Arancio O, Belzung C, Hen R. Requirement of hippocampal neurogenesis for the behavioral effects of antidepressants. Science. 2003; 301:805-809. [PubMed: 12907793]

Sapolsky RM, Meaney MJ. Maturation of the adrenocortical stress response: neuroendocrine control mechanisms and the stress hyporesponsive period. Brain Res. 1986; 396:64-76. [PubMed: 3011218]

Sarkar A, Chachra P, Kennedy P, Pena CJ, Desouza LA, Nestler EJ, Vaidya VA. Hippocampal HDAC4 Contributes to Postnatal Fluoxetine-Evoked Depression-Like Behavior.

Neuropsychopharmacology: official publication of the American College of Neuropsychopharmacology. 2014

Sillaber I, Panhuysen M, Henniger MS, Ohl F, Kuhne C, Putz B, Pohl T, Deussing JM, Paez-Pereda M, Holsboer F. Profiling of behavioral changes and hippocampal gene expression in mice chronically treated with the SSRI paroxetine. Psychopharmacology (Berl). 2008; 200:557-572. [PubMed: 18629477]

Simmons RK, Stringfellow SA, Glover ME, Wagle AA, Clinton SM. DNA methylation markers in the postnatal developing rat brain. Brain Res. 2013; 1533:26-36. [PubMed: 23954679]

Simpson KL, Weaver KJ, de Villers-Sidani E, Lu JY, Cai Z, Pang Y, Rodriguez-Porcel F, Paul IA, Merzenich M, Lin RC. Perinatal antidepressant exposure alters cortical network function in rodents. Proc Natl Acad Sci U S A. 2011; 108:18465-18470. [PubMed: 22025710]

Stead JD, Clinton S, Neal C, Schneider J, Jama A, Miller S, Vazquez DM, Watson SJ, Akil H. Selective breeding for divergence in novelty-seeking traits: heritability and enrichment in spontaneous anxiety-related behaviors. Behav Genet. 2006a; 36:697-712. [PubMed: 16502134]

Stead JD, Neal C, Meng F, Wang Y, Evans S, Vazquez DM, Watson SJ, Akil H. Transcriptional profiling of the developing rat brain reveals that the most dramatic regional differentiation in gene expression occurs postpartum. Journal of Neuroscience. 2006b; 26:345-353. [PubMed: 16399705]

Stedenfeld KA, Clinton SM, Kerman IA, Akil H, Watson SJ, Sved AF. Novelty-seeking behavior predicts vulnerability in a rodent model of depression. Physiol Behav. 2011; 103:210-216. [PubMed: 21303678]

Thompson MR, Li KM, Clemens KJ, Gurtman CG, Hunt GE, Cornish JL, McGregor IS. Chronic fluoxetine treatment partly attenuates the long-term anxiety and depressive symptoms induced by MDMA ('Ecstasy') in rats. Neuropsychopharmacology. 2004; 29:694-704. [PubMed: 14627999]

Van den Hove DL, Blanco CE, Scheepens A, Desbonnet L, Myint AM, Leonard BE, Prickaerts J, Steinbusch HW. Prenatal maternal paroxetine treatment and neonatal mortality in the rat: a preliminary study. Neonatology. 2008; 93:52-55. [PubMed: 17652957]

Vasilakis-Scaramozza C, Aschengrau A, Cabral H, Jick SS. Antidepressant use during early pregnancy and the risk of congenital anomalies. Pharmacotherapy. 2013; 33:693-700. [PubMed: 23744675]

Vazquez-Palacios G, Bonilla-Jaime H, Velazquez-Moctezuma J. Antidepressant effects of nicotine and fluoxetine in an animal model of depression induced by neonatal treatment with clomipramine. Prog Neuropsychopharmacol Biol Psychiatry. 2005; 29:39-46. [PubMed: 15610943]

Veenema AH, Torner L, Blume A, Beiderbeck DI, Neumann ID. Low inborn anxiety correlates with high intermale aggression: link to ACTH response and neuronal activation of the hypothalamic paraventricular nucleus. Horm Behav. 2007; 51:11-19. [PubMed: 16935287]

Velazquez-Moctezuma J, Diaz Ruiz O. Neonatal treatment with clomipramine increased immobility in the forced swim test: an attribute of animal models of depression. Pharmacol Biochem Behav. 1992; 42:737-739. [PubMed: 1513855]

Verheij MM, Veenvliet JV, Groot Kormelink T, Steenhof M, Cools AR. Individual differences in the sensitivity to serotonergic drugs: a pharmacobehavioural approach using rats selected on the basis of their response to novelty. Psychopharmacology (Berl). 2009; 205:441-455. [PubMed: 19434397] 
Vijayakumar M, Meti BL. Alterations in the levels of monoamines in discrete brain regions of clomipramine-induced animal model of endogenous depression. Neurochem Res. 1999; 24:345349. [PubMed: 10215507]

Vogel G, Neill D, Hagler M, Kors D. A new animal model of endogenous depression: a summary of present findings. Neurosci Biobehav Rev. 1990; 14:85-91. [PubMed: 2183099]

Vorhees CV, Acuff-Smith KD, Schilling MA, Fisher JE, Moran MS, Buelke-Sam J. A developmental neurotoxicity evaluation of the effects of prenatal exposure to fluoxetine in rats. Fundam Appl Toxicol. 1994; 23:194-205. [PubMed: 7982528]

Weaver KJ, Paul IA, Lin RC, Simpson KL. Neonatal exposure to citalopram selectively alters the expression of the serotonin transporter in the hippocampus: dose-dependent effects. Anat Rec (Hoboken). 2010; 293:1920-1932. [PubMed: 20830689]

White DA, Kalinichev M, Holtzman SG. Locomotor response to novelty as a predictor of reactivity to aversive stimuli in the rat. Brain Res. 2007; 1149:141-148. [PubMed: 17383617]

Wichman CL, Moore KM, Lang TR, St Sauver JL, Heise RH Jr, Watson WJ. Congenital heart disease associated with selective serotonin reuptake inhibitor use during pregnancy. Mayo Clin Proc. 2009; 84:23-27. [PubMed: 19121250]

Willner P. Chronic mild stress (CMS) revisited: consistency and behavioural-neurobiological concordance in the effects of CMS. Neuropsychobiology. 2005; 52:90-110. [PubMed: 16037678]

Wogelius P, Norgaard M, Gislum M, Pedersen L, Munk E, Mortensen PB, Lipworth L, Sorensen HT. Maternal use of selective serotonin reuptake inhibitors and risk of congenital malformations. Epidemiology. 2006; 17:701-704. [PubMed: 17028507]

Yang D, Li Q, Fang L, Cheng K, Zhang R, Zheng P, Zhan Q, Qi Z, Zhong S, Xie P. Reduced neurogenesis and pre-synaptic dysfunction in the olfactory bulb of a rat model of depression. Neuroscience. 2011; 192:609-618. [PubMed: 21722712]

Yannielli PC, Kargieman L, Gregoretti L, Cardinali DP. Effects of neonatal clomipramine treatment on locomotor activity, anxiety-related behavior and serotonin turnover in Syrian hamsters. Neuropsychobiology. 1999; 39:200-206. [PubMed: 10343185]

Ying SY, Gove S, Fang VERSUS, Greep RO. Ovulation in postpartum rats. Endocrinology. 1973; 92:108-116. [PubMed: 4681917]

Yonkers KA, Wisner KL, Stewart DE, Oberlander TF, Dell DL, Stotland N, Ramin S, Chaudron L, Lockwood C. The management of depression during pregnancy: a report from the American Psychiatric Association and the American College of Obstetricians and Gynecologists. Obstet Gynecol. 2009; 114:703-713. [PubMed: 19701065]

Yoo HS, Bunnell BN, Crabbe JB, Kalish LR, Dishman RK. Failure of neonatal clomipramine treatment to alter forced swim immobility: chronic treadmill or activity-wheel running and imipramine. Physiol Behav. 2000; 70:407-411. [PubMed: 11006441]

Zeskind PS, Stephens LE. Maternal selective serotonin reuptake inhibitor use during pregnancy and newborn neurobehavior. Pediatrics. 2004; 113:368-375. [PubMed: 14754951]

Zhang J, Darling RD, Paul IA, Simpson KL, Chen K, Shih JC, Lin RC. Altered expression of tyrosine hydroxylase in the locus coeruleus noradrenergic system in citalopram neonatally exposed rats and monoamine oxidase a knock out mice. Anat Rec (Hoboken). 2011; 294:1685-1697. [PubMed: 21901841] 


\section{Highlights}

- Neonatal SSRI exposure adversely affects brain development and emotional behavior.

- Some individuals are especially vulnerable to perinatal SSRI exposure, but causes are unknown.

- We present a rodent model of differential vulnerability to perinatal SSRI exposure.

- Rats prone to high depression-like behavior are vulnerable to perinatal paroxetine exposure.

- Perinatal paroxetine alters developmental gene expression in the hippocampus and amygdala. 


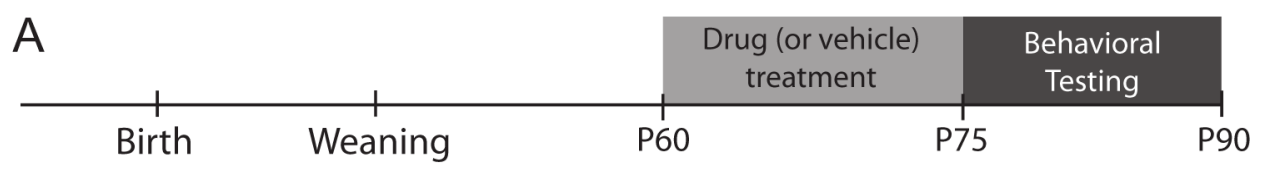

B

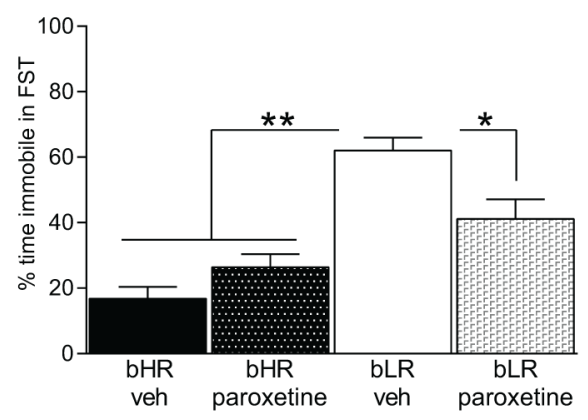

D

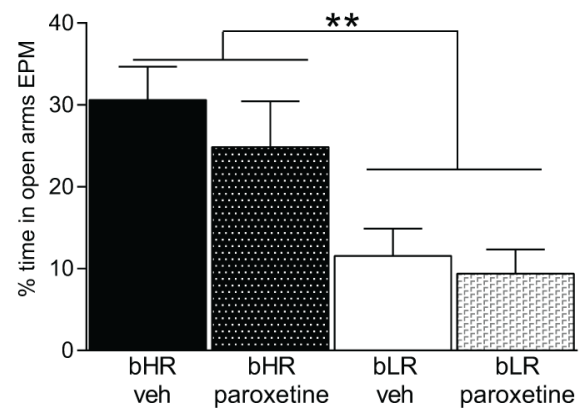

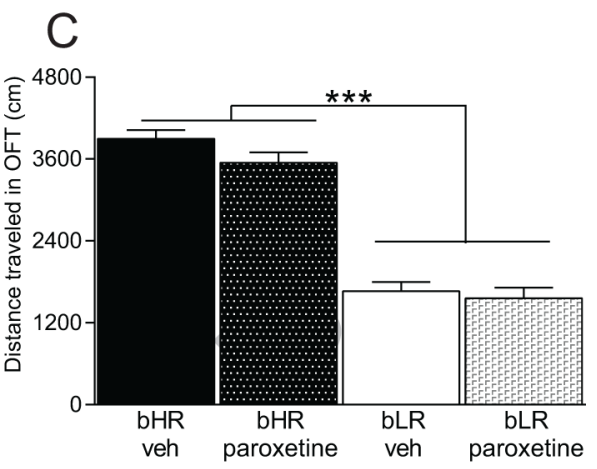

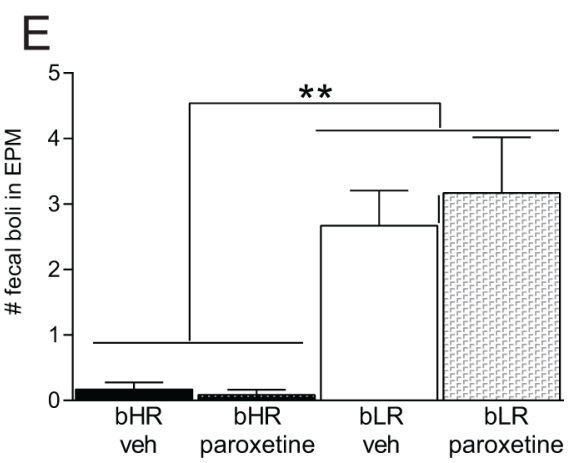

Figure 1. Treating adult rats with the SSRI paroxetine improves bLRs' depression-like behavior, but has no effect on bHRs

(A) Experimental timeline showing that adult bHR and bLR males were chronically treated with the SSRI paroxetine $(10 \mathrm{mg} / \mathrm{kg} / \mathrm{day}$, p.o.) for two weeks prior to behavioral evaluation and throughout testing. (B) Vehicle-treated bLRs spent significantly more time immobile in the forced swim test (FST) compared to bHR rats, although chronic paroxetine treatment improved bLRs' depression-like behavior, leading to reduced FST immobility. bHRs' FST performance was not affected by paroxetine treatment. (C) bHR rats generally exhibited greater locomotor response to novelty (distance traveled in the Open Field Test; OFT) compared to the bLR groups; paroxetine treatment had no effect on either strain in the OFT. (D) In the Elevated Plus Maze (EPM), both bHR groups spent significantly more time in the open arms compared to bLR animals; paroxetine treatment had no effect on this measure in either strain. (E) bLR exhibited significantly greater stress-induced defecation in the EPM compared to bHRs; paroxetine treatment had no effect on this measure in either strain. * indicates $\mathrm{p}<0.05 ; * *$ indicates $\mathrm{p}<0.01 ; * * *$ indicates $\mathrm{p}<0.001$ 
A

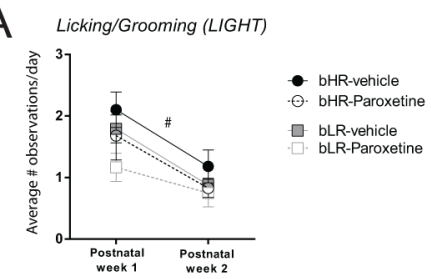

C Arched-Back Nursing (LIGHT)

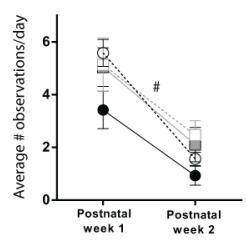

$\mathrm{E}$

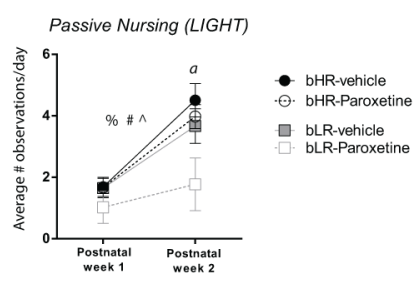

G

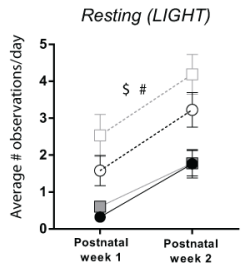

- bHR-vehicle
$-\odot$ bHR-Paroxetine

bLR-vehicle
-7. bLR-Paroxetine
B Licking/Grooming (DARK)

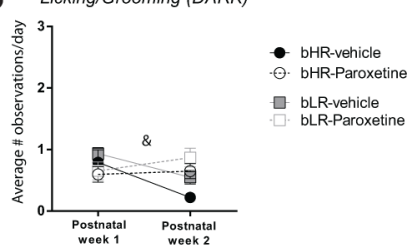

D Arched-Back Nursing (DARK)

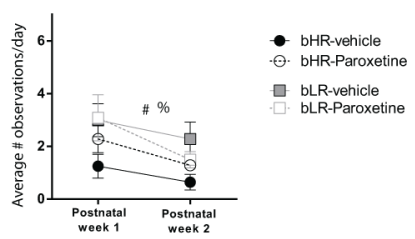

F Passive Nursing (DARK)

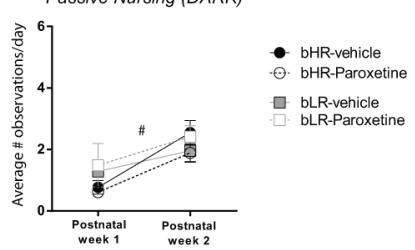

$\mathrm{H}$

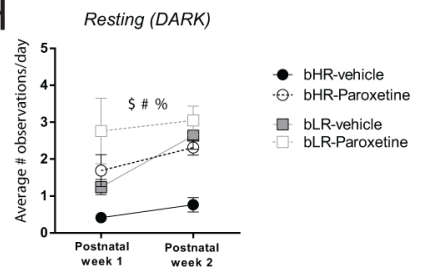

Figure 2. Paroxetine treatment has minimal effects on bHR/bLR maternal behavior Graphs depict the average number of daily behavioral observations during the first two postpartum weeks, with data shown separately for the light phase (left column A, C, E, G) and dark phase (right column $\mathbf{B}, \mathbf{D}, \mathbf{F}, \mathbf{H})$. (A) All mothers displayed more licking/grooming behavior during the light phase of postpartum week one versus two. (B) There was a week $\mathrm{x}$ treatment interaction on licking/grooming in the dark phase. There were no clear effects of paroxetine treatment or bHR/bLR phenotype on licking/grooming behavior. (C) Dams displayed more arched-back nursing during the light phase of postnatal week one versus two, with no effects of paroxetine or bHR/bLR phenotype. (D) Dams displayed more arched-back nursing during the dark phase of week one versus week two. There was a main effect of phenotype on arched-back nursing, with bLRs exhibiting more arched-back nursing than bHRs. (E) Most dams dramatically increased their amount of passive nursing during the light phase from postnatal week one to two. However, there was a marked effect of paroxetine treatment on passive nursing, specifically within bLR dams, since they showed less passive nursing than the other groups during the light phase. (F) Dams spent more time passive nursing during the dark phase in week one versus week two, but there was no effect of phenotype or treatment. (G) The dams generally spent more time resting during the light phase during the second versus first postnatal week, although, interestingly, paroxetine- 
treated dams (both bHR and bLR females) spent more time resting than vehicle-treated dams. (H) During the dark phase, dams spent more time resting in week two versus week one. There was a main effect of phenotype, with bLRs generally displaying more time resting compared to bHR dams. There was also an effect of paroxetine treatment, with paroxetine-treated dams (both bHR and bLR females) exhibiting increased resting in the dark phase. \# indicates main effect on postnatal week; $\$$ indicates main effect of paroxetine treatment; $\%$ indicates main effect of bHR/bLR phenotype, \& indicates a week x treatment interaction; ^ indicates a week x phenotype interaction; $a$ indicates bLR-Paroxetine is significantly reduced compared to any of the 3 other conditions ( $\mathrm{p}<0.007)$. 

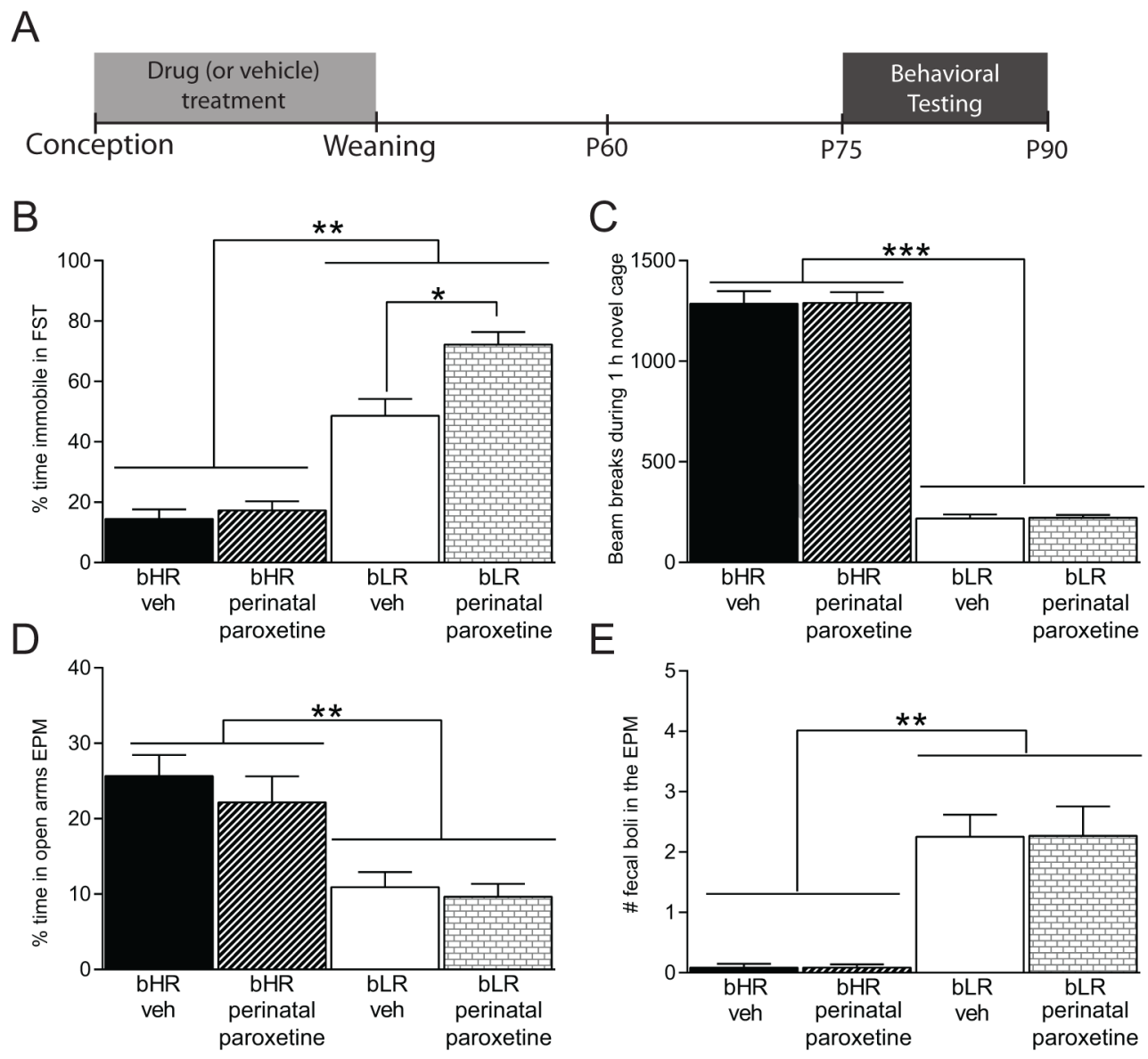

Figure 3. Perinatal exposure to the SSRI paroxetine exacerbates bLR offspring's adult depression-like behavior, but has no effect on bHR offspring

(A) Experimental timeline showing that adult bHR/bLR females were treated with the SSRI paroxetine $(10 \mathrm{mg} / \mathrm{kg} / \mathrm{day}$, p.o.) for one week prior to mating, throughout gestation until the offspring were weaned on postnatal day (P)21. Adult male offspring underwent behavioral assessment beginning on P75. (B) bLR rats generally exhibited greater forced swim test (FST) immobility compared to bHR rats. However, bLR offspring that were exposed to perinatal paroxetine treatment showed even greater FST immobility compared to vehicleexposed bLR offspring. bHR offspring, on the other hand, were unaffected by the perinatal SSRI exposure. (C) bHRs showed greater novelty-induced locomotion compared to bLRs but perinatal paroxetine exposure did not affect this measure in either strain. (D) In the Elevated Plus Maze (EPM), both bHR groups spent more time in the open arms compared to bLRs, with no effect of perinatal paroxetine on either group. (E) bLR rats showed greater stress-induced defecation than bHRs in the EPM, but perinatal SSRI exposure did not affect this measure for either group. * indicates $\mathrm{p}<0.05 ; * *$ indicates $\mathrm{p}<0.01$ 

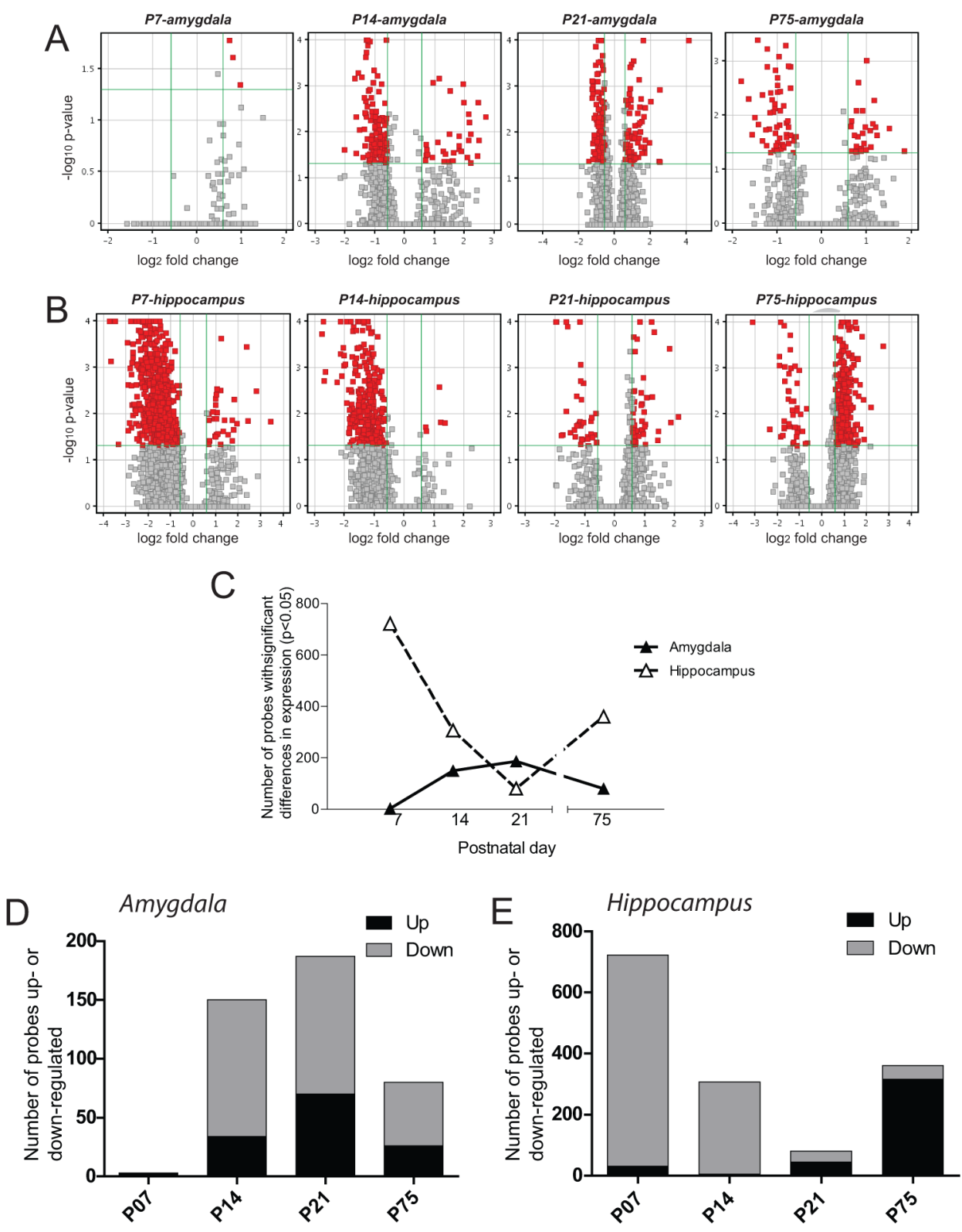

Figure 4. Perinatal SSRI exposure induces marked developmental gene expression changes in bLR hippocampus and amygdala

Adult bLR females were treated with the SSRI paroxetine $(10 \mathrm{mg} / \mathrm{kg} / \mathrm{day}$, p.o. $)$ or vehicle for one week prior to mating, throughout gestation until the offspring were weaned on postnatal day (P)21. Groups of male offspring were sacrificed on postnatal day (P)7, P14, P21, and P75 and hippocampal and amygdalar tissue was dissected for microarray experiments. Lists of genes that were significantly altered by perinatal SSRI treatment were selected based on volcano plot filtering with a fold change $(\mathrm{FC})$ cut-off $>1.5$, and p-value $<0.05$ following Bonferroni FWER multiple test correction. Volcano plots show data for the (A) hippocampus and (B) amygdala at each developmental timepoint. (C) In the amygdala, perinatal SSRI exposure lead to few gene expression changes at P7 (when only 3 genes were altered), but steadily greater numbers of altered genes from P14 through adulthood (P75; 
black triangles, solid line). In the hippocampus, perinatal SSRI exposure altered expression of several hundred genes at P7. The number of altered genes in the hippocampus steadily dropped to 80 genes by P21, but resurged to 360 altered genes by adulthood (white triangles, dashed line). (D) Of the differentially expressed transcripts in the developing amygdala, all 3 were up-regulated at P7 while the majority of transcripts were down-regulated at P14, P21, and P75. (E) In the hippocampus, the vast majority of differentially expressed genes were down-regulated at P7 and P14; however, by P75 almost all of the differentially expressed genes were up-regulated. 
A
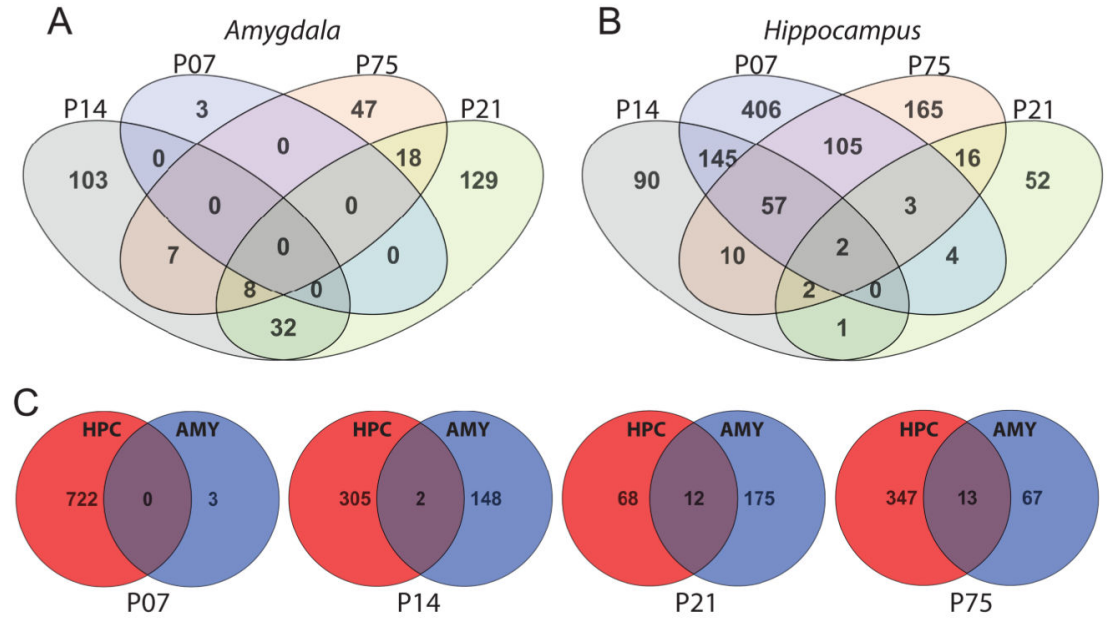

Figure 5. Perinatal SSRI exposure differentially impacts the transcriptomes of the hippocampus and amygdala

Venn diagrams were generated in GeneSpring (v12.6) to demonstrate the number of gene transcripts that were altered by perinatal paroxetine exposure across multiple developmental ages (A \& B) or in the both amygdala and hippocampus (C). (A) In the amygdala, few genes were differentially regulated across multiple ages: 32 genes were differentially expressed in the amygdala at both P14 and P21; 18 genes at both P21 and P75; 7 genes at both P14 and $\mathrm{P} 75$; and 8 genes at P14, P21, and P75. The three genes that were differentially expressed in the P7 amygdala were not altered at later ages. (B) In the hippocampus, 145 genes were differentially regulated at P7 and P14; 105 genes at P7 and P75; and 57 genes at P7, P14, and P75. Two genes were differentially regulated in all 4 time points analyzed (Calm2, NM_017326; Psmd1, NM_031978) (C) There was surprisingly little overlap in the genes altered by perinatal SSRI exposure in the developing amygdala (AMY) and hippocampus (HPC). Zero transcripts were commonly changed in the HPC and AMY at P7, with 2 genes overlapping at P14, 12 genes overlapping at P21, and 13 overlapping genes at P75. 


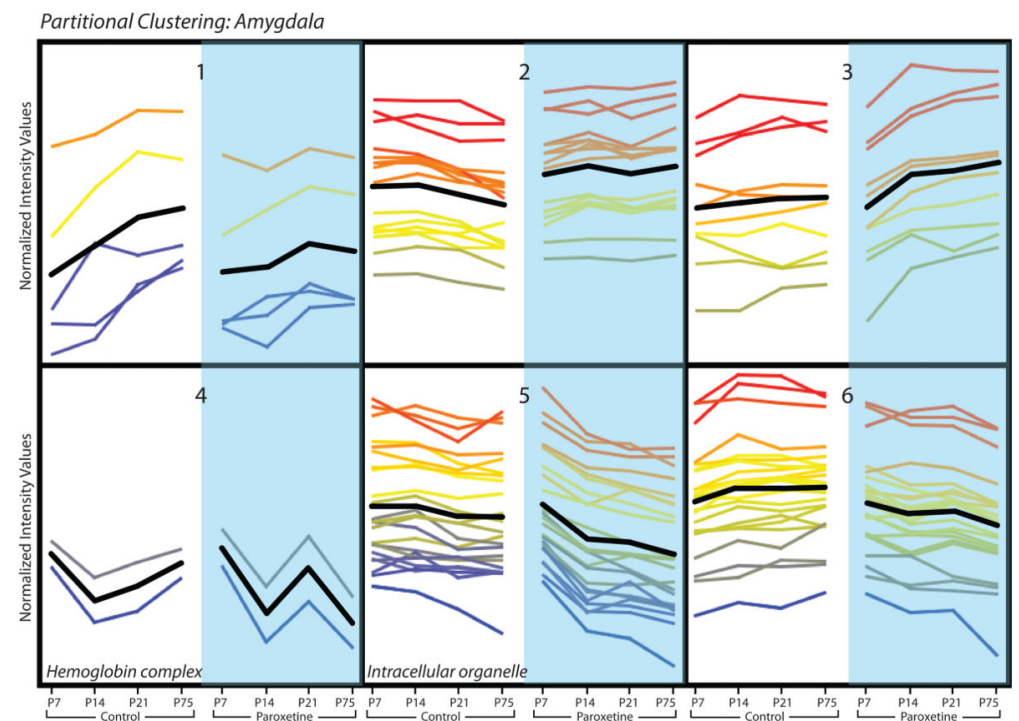

Figure 6. Partitional clustering of gene expression profiles in amygdala following perinatal SSRI exposure

Partitional clusters were generated in GeneSpring (v12.6). In the amygdala data set, 80 genes that passed volcano plot filtering in the P75 data were assigned to 6 clusters based on similarity of expression profiles (shown in normalized intensity values on the y-axis). Developmental gene expression patterns from P7 through P75 are shown from left to right for perinatal vehicle-exposed controls (white background, left) and perinatal SSRI-exposed (blue background, right) bLR offspring. Time points are shown with equidistant spacing despite different intervals between some of the time points. Each line represents a gene, and line color reflects normalized intensity value at P75 in the SSRI-exposed group (far right point in each cluster). The black line indicates mean expression profile for each cluster. GO analysis of transcripts within each cluster revealed significant enrichment for specific GO terms in clusters 4 (GO:0005833, hemoglobin complex; $p=0.0000504)$ and 5 (GO: 0043229, intracellular organelle; $p=0.033)(\mathrm{p}<0.05$ after multiple test correction). 


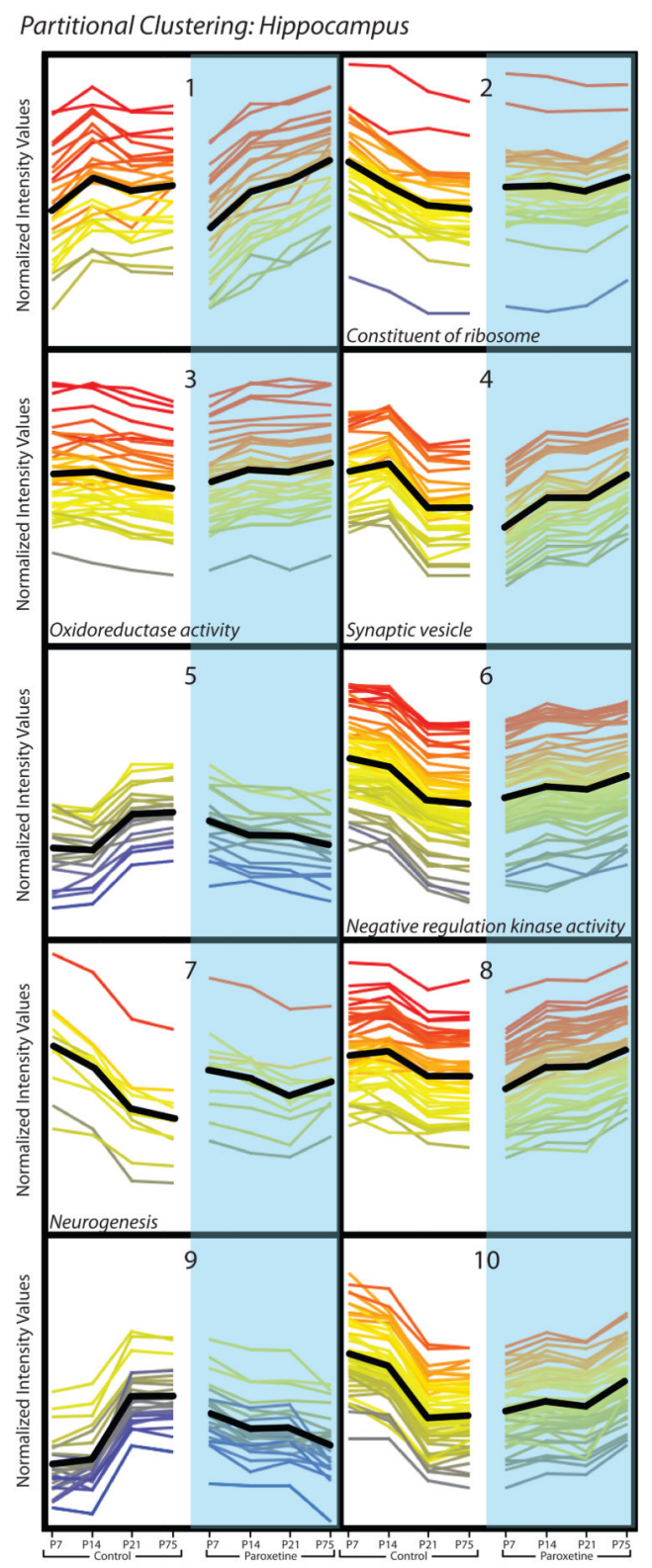

Figure 7. Partitional clustering of gene expression profiles in hippocampus following perinatal SSRI exposure

Partitional clusters were generated in GeneSpring (v12.6). In the hippocampus data set, 360 genes that passed volcano plot filtering in the P75 data were assigned to 10 clusters based on similarity of expression profiles (shown in normalized intensity values on the y-axis).

Developmental gene expression patterns from P7 through P75 are shown from left to right for perinatal vehicle-exposed controls (white background, left) and perinatal SSRI-exposed (blue background, right) bLR offspring. Time points are shown with equidistant spacing despite different intervals between some of the time points. Each line represents a gene, and line color reflects normalized intensity value at P75 in the SSRI-exposed group (far right point in each cluster). The black line indicates mean expression profile for each cluster. GO analysis of genes in each cluster revealed significant enrichment for specific GO terms in 
cluster 2 (GO:0003735-GO:0003742, structural constituent of ribosome; $p=4.81 \times$ $10^{-13}$ ), cluster 3 (GO:0016676, oxidoreductase activity, acting on a heme group of donors, oxygen as acceptor; $p=0.05)$, cluster $4(G O: 0008021$, synaptic vesicle; $p=0.034)$, cluster 6 (GO:0033673, negative regulation of kinase activity; $p=0.039)$, and cluster 7 (GO: 0022008, neurogenesis; $p=0.006$ ) ( $\mathrm{p}<0.05$ after multiple test correction). 